\title{
Synthesis and Single Molecule Force Spectroscopy of Graft Copolymers of Poly(2-hydroxyethyl methacrylate-g-ethylene glycol)
}

\section{Dong Zhang and Christine Ortiz*}

Department of Materials Science and Engineering, Massachusetts I nstitute of Technology, RM 13-4022, 77 Massachusetts Avenue, Cambridge, Massachusetts 02139

Received J uly 23, 2003; Revised Manuscript Received December 10, 2003

\begin{abstract}
In this study, an end-functionalized graft copolymer, thiol-terminated poly(2-hydroxyethyl methacrylate-g-ethylene glycol) or SH-poly(HEMA-g-EG), was synthesized by the atom transfer radical polymerization (ATRP) method and then characterized by ${ }^{1} \mathrm{H}$ nuclear magnetic resonance (NMR), gel permeation chromatography (GPC), and light scattering (LS). The polymer was covalently end-grafted to an $\mathrm{Au}$ substrate at low enough grafting densities to produce well-separated individual polymer "mushrooms" and single molecule force spectroscopy (SMFS) was then employed to measure the single polymer extensional elastic properties in phosphate buffered saline solution (PBS, ionic strength (IS) = $0.15 \mathrm{M}, \mathrm{pH}=7.4)$ and deionized $\mathrm{H}_{2} \mathrm{O}\left(\mathrm{IS} \sim 6 \times 10^{-5} \mathrm{M}, \mathrm{pH}=5\right)$. In both solvents, the polymer behaved as an extensible freely jointed chain with a statistical segment length, $a=0.52 \pm 0.09 \mathrm{~nm}$, and a segment elasticity, $\mathrm{k}_{\text {segment }}=10.5 \pm 3.3 \mathrm{~N} / \mathrm{m}$, in PBS and $\mathrm{a}=1.03 \pm 0.01 \mathrm{~nm}$ and $\mathrm{k}_{\text {segment }}=4.2 \pm 0.5 \mathrm{~N} / \mathrm{m} \mathrm{in} \mathrm{H}_{2} \mathrm{O}$. Comparison to the known single molecule elasticity behavior for the PEG homopolymer suggests a smaller number and/or smaller magnitude of the noncovalent inter- and intramolecular interactions along the HEMA backbone and that even at this low PEG side chain grafting density, the side chains are still quite effective in causing local expansion of the PHE MA backbone by overcoming hydrophobic collapsing forces relative to the PHEMA homopolymer. Since the PEG chains are still well-solvated in PBS, one explanation for the small variation in nanomechanical properties with solvent is that in PBS the salt ions compete for and weaken the inter-and intramolecular $\mathrm{H}$-bonding that does exist al ong the PHEMA backbone, causing a local contraction and an increased segmental stiffness due to the reduced noncovalent nature of the segments.
\end{abstract}

\section{Introduction}

Functional nanometer-scale devices have now become a reality; for example, carbon nanotube "nanotweezers", 1 molecular junctions consisting of an individual organic conducting molecule between two gold leads, ${ }^{2}$ and metallic wires consisting of a single row of gold atoms. ${ }^{3}$ Individual or a few polymer chains will soon be able to be incorporated into such devices to function as molecular springs, switches, sensors, shock absorbers, and motors to impart adhesive control and serve as the basic components for dynamic assemblies-just as they do in biological systems. In biological systems, macromolecular elastic "spring" properties, as well as other properties, are controlled through the precise incorporation and organization of multiple, noncovalent intramol ecular interactions (e.g., electrostatic, hydrophobic, Hbonds, van der Waals forces, etc.). For synthetic systems, a comprehensive knowledge of the molecular-level forces and deformations involved will be needed for appropriate design and maximum efficiency and reliability. With the advent of single molecule force spectroscopy (SMFS), ${ }^{4-6}$ which is the direct measurement of the elasticity of individual macromolecules, single macromolecule nanomechanical design is fast becoming a reality.

In this paper, we explore the possibility of using combtype graft copolymers to control single molecule nanomechanical properties, i.e., the force vs chain end-toend separation distance profile, spring constant, extensibility, heterogeneity, nonlinearity, strain hardening, etc. The general concept is to impart differences in non-

* Corresponding author: e-mail cortiz@mit.edu. covalent intramolecular interactions between the side chains and main chain backbone and /or solvent resulting in different equilibrium conformations, where systematic variation and control of the nanomechanical properties can potentially be achieved through the length of side chain, the side chain grafting density, and the type of side chain-main chain interactions. One may think of this as the nanotechnological anal ogue of understanding structure-property relationships and controlling the stress vs strain curve of a macroscopic material. In addition, stimulus-responsive properties may be achieved by using polyelectrolyte side chain or main chains or by using any interactions that are sensitive to environmental conditions such as solution $\mathrm{pH}$ and ionic strength.

Our first model system chosen was poly(2-hydroxyethyl methacrylate-g-ethylene glycol ) or poly(HEMA-gEG). Both PHEMA and PEG homopolymers, copolymers, and cross-linked networks (e.g., hydrogels) are well-studied, technologically important materials used extensively for biomedical applications such as intramolecular and soft contact lenses, coatings for bloodcontacting devices and surgical sutures, artificial soft tissue replacements such as postsurgical construction of female breasts and nasal cartilages, wound (burn) dressings, and drug delivery. ${ }^{7-13}$ PEG is neutral, highly mobile, hydrophilic, and water-soluble at room temperature due to its strong tendency to form $\mathrm{H}$-bonds with water via the - $\mathrm{O}-$ groups and has a large excluded volume, low van der Waals interactions, and lower critical solution temperature (LCST) or inverse temperature solubility. ${ }^{14}$ It is also known to contain some degree of hydrophobicity due to the $-\mathrm{CH}_{2}-\mathrm{CH}_{2}-$ groups 
since it is soluble in some organic solvents, ${ }^{14}$ adsorbs to hydrophobic surfaces and the air - water interface, ${ }^{15-19}$ and is used as a surfactant in a number of applications. ${ }^{20-22}$ PHEMA is also neutral, and al though higher molecular weight PHEMA is known to be somewhat hydrophilic and has a relatively high degree of hydration. ${ }^{24 a}$ PHEMA with degrees of polymerization $\mathrm{DP}_{\mathrm{n}} \geq$ 40 starts to exhibit insoluble fractions and also a LCST. ${ }^{24 b}$ PHEMA can form $\mathrm{H}$-bonds with water or itself through the $-\mathrm{OH}$ or $-\mathrm{O}-\mathrm{C}=\mathrm{O}$ groups. $\mathrm{PHEMA}$ is also expected to have some hydrophobic interactions between $-\mathrm{CH}_{2}-$ groups and a high van der Waals attractive interaction, since it is reported to have a high refractive index of 1.512 .23

The technique of atom transfer radical polymerization (ATRP) ${ }^{26-35}$ was chosen to synthesize the poly(HEMA$\mathrm{g}$-EG) model system described in this paper for a number of reasons. ATRP is an excellent general method to synthesize statistical, gradient, block, and graft copolymers as well as star and hyperbranched polymers due to the facile availability of functional monomers, halogen initiators, and catalysts. ATRP is able to synthesize well-defined polymers with low polydispersities and controlled molecular weights, partially because a living polymerization is easily controlled, and a radical process is very tolerant of impurities and other functionalities in the monomer. In addition, ATRP was employed here to synthesize the target polymer in (mono)thiol-terminated form, SH-poly(HEMA-g-EG), so that a strong tether could be formed between the polymer chain end and an Au surface, facilitating the ease of SMFS experiments. Our long-term plans are to synthesize graft copolymers with different graft density, graft length, and side chains as well as the introduction of functional groups to the polymers such as $-\mathrm{COOH}$ groups in poly(MAA-g-EG) to create stimulus responsive architectures which vary as a function of $\mathrm{pH}$ and solution ionic strength.

\section{Experimental Section}

Materials. 2-Mercaptoethanol (98\%), 2,4-dinitrofluorobenzene (99\%), 2-bromoisobutyryl bromide (98\%), 2-hydroxyethyl methacrylate (97\%), poly(ethylene glycol) methyl ether methacrylate, 2,2'-dipyridyl (bpy, 99\%), triethylamine (99.5\%), tetramethylsilane (TMS, 99.9\%), chloroform-d, toluene $(99.8 \%$, HPLC grade), N,N-dimethylformamide (DMF, 99.9\%, HPLC grade), and copper (I ) bromide (99.999\%) were purchased from Aldrich. Methanol- $d_{4}$ (99.8\%) from Cambridge I sotope Laboratories was used as received. De-Hibit 200 resin was obtained from Polysciences. Polystyrene (PS) standards with $\mathrm{M}_{\mathrm{w}}$ of 382 100, 44 000, 29 300, 13 700, and 2430 were obtained from Aldrich. Poly(methyl methacrylate) (PMMA) standards with $M_{w}$ of 350000 from Polysciences and 143000, 75000, 68000 , 50 100, and 6540 from Polymer Laboratory were obtained. Poly(ethylene glycol) (PEG) standards with $M_{w}$ of 30800 , 53 500, and 2100 and $M_{w}$ of 93 750, 73 400, and 18300 were obtained from Polymer Source and Polymer Laboratory, respectively. All water used for solutions, rinsing, and storage was deionized (18 $\mathrm{M} \Omega \cdot \mathrm{cm}$ resistance, Purelab Plus UV/UF, US filter) and are known to have $\mathrm{pH} \sim 5$ and an ionic strength IS $\sim 6 \times 10^{-5} \mathrm{M} .^{48}$ Phosphate buffered saline tablets (PBS) were purchased from Sigma, and PBS solutions were prepared by dissolving one tablet in $200 \mathrm{~mL}$ of water to obtain $0.01 \mathrm{M}$ phosphate buffer, $0.003 \mathrm{M} \mathrm{KCl}$, and $0.137 \mathrm{M} \mathrm{NaCl}(0.15 \mathrm{M}$ total), $\mathrm{pH} 7.4$ at $25^{\circ} \mathrm{C}$. Silicon wafers with $\mathrm{N}$ type and 100 orientation were purchased from Crystaltek. Chromium from R. D. Mathis and gold (99.99\%) from J \& J Materials were used as received. All the other chemicals were received from commercial suppliers and used without further purification.

Synthesis of 2-(2,4-Dinitrophenylthio)ethyl 2-Bromo2-methylpropionate (DPEBM). The DPEBM was synthe- a

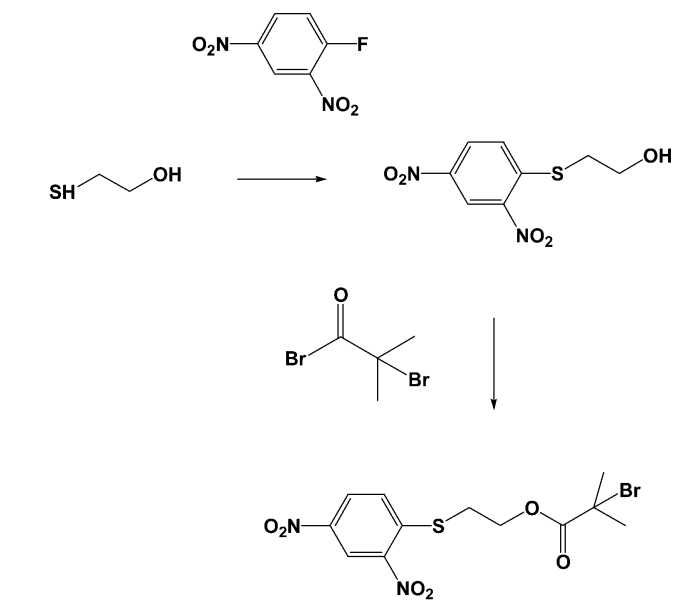

$\sum_{\mathrm{OH}}^{b}=\mathrm{O}$
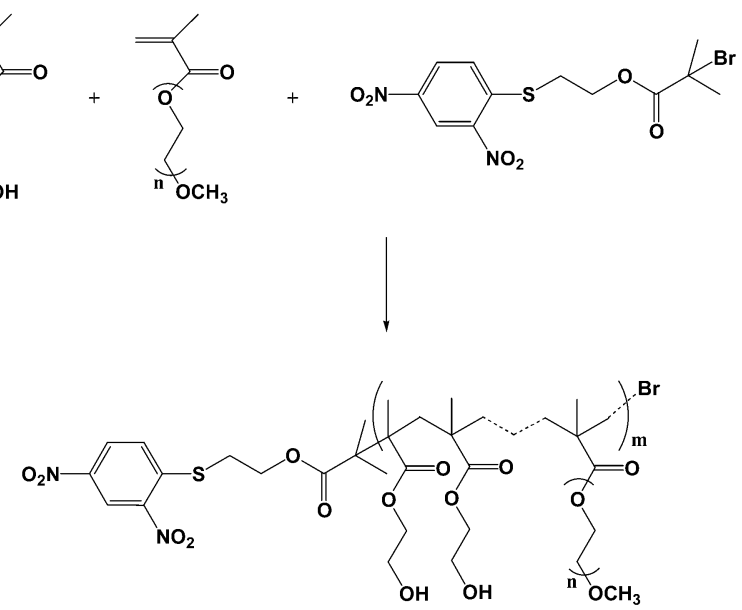

$\mathrm{SH}^{\mathrm{OH}}$

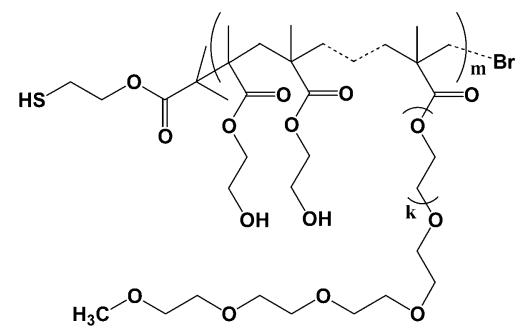

Figure 1. Synthesis of DPEBM (a) and SH-poly(HEMA-g$\mathrm{EG})(\mathrm{b})$.

sized according to a procedure described el sewhere with some modifications as shown in Figure la. ${ }^{36-38}$ In a $250 \mathrm{~mL}$, three necked round-bottom flask equipped with a condenser and paddle stirrer, $2.10 \mathrm{~g}$ of mercaptoethanol dissolved in $20 \mathrm{~mL}$ of $\mathrm{CHCl}_{3}$ was slowly added to a mixture of $5.00 \mathrm{~g}$ of 2,4dinitrofluorobenzene and $8.14 \mathrm{~g} \mathrm{Et}_{3} \mathrm{~N}$ in $30 \mathrm{~mL}$ of $\mathrm{CHCl}_{3}$. The reaction flask was loosely stoppered to restrict the exposure to atmospheric moisture. The reaction mixture was stirred for $15 \mathrm{~h}$ at room temperature and poured into $2 \mathrm{M} \mathrm{HCl}$. A yellow crystal was separated from the water phase and was washed with distilled water. The product was filtered, washed with water, and then dried at $25^{\circ} \mathrm{C}$ in a vacuum oven $(5$ $\mathrm{mmHg}$ ) overnight to yield yellow crystals. For further purification, chlor oform was used to extract the product. The extraction solvent was isolated by filtration and held in air overnight to allow crystallization. The crystal was filtered and dried at $25{ }^{\circ} \mathrm{C}$ in a vacuum overnight to yield $4.20 \mathrm{~g}$ of $2-(2,4-$ dinitrophenylthio)ethanol as a yellow crystalline phase. 
In a $250 \mathrm{~mL}$, three-neck flask fitted with an addition funnel, condenser, and paddle stirrer, $4.26 \mathrm{~g}$ of 2-bromoisobutyryl bromide dissolved in $60 \mathrm{~mL}$ of $\mathrm{CHCl}_{3}$ was added dropwise with stirring to a solution of $3.0 \mathrm{~g}$ of 2-(2,4-dinitrophenylthio)ethanol and $4.26 \mathrm{~g}$ of $\mathrm{Et}_{3} \mathrm{~N}$ in $60 \mathrm{~mL}$ of $\mathrm{CHCl}_{3}$. The solution was maintained at room temperature for $12 \mathrm{~h}$ and extracted twice by $1 \mathrm{M} \mathrm{HCl}$ and distilled water. The product was isolated by suction filtration and dried at $25^{\circ} \mathrm{C}$ in a vacuum overnight to yield yellow crystals. For further purification, methanol was used to extract the product, and the extraction solvent was held in air to crystallize. The crystal was filtered and dried at $25^{\circ} \mathrm{C}$ in a vacuum overnight to yield DPEBM as a yellow crystalline phase.

Synthesis of SH-Poly(HEMA-g-E G). In a typical polymerization (F igure $1 b$ ), a $250 \mathrm{~mL}$, three-neck round-bottom flask was equipped with a condenser, argon inlet, and paddle stirrer. Inhibitors in monomers were removed by the De-Hibit 200 resin. To $19.1 \mathrm{~g}$ of 2-hydroxyethyl methacrylate and $6.8 \mathrm{~g}$ of poly(ethylene glycol) methyl ether methacrylate were added $0.158 \mathrm{~g}$ of bpy ligand, $0.057 \mathrm{~g}$ of $\mathrm{CuBr}$, and $12.5 \mathrm{~g}$ of methanol. Then $0.157 \mathrm{~g}$ of DPEBM was added to the stirred solution at room temperature, followed by purging with argon to remove oxygen. The polymer molecular weight could be controlled by adding different concentrations of the catalyst, initiator, and ligand. To produce lower molecular weight polymer, the catalyst, initiator, and ligand were $0.057,0.157$, and $0.158 \mathrm{~g}$, respectively. To produce higher molecular weight polymer, the catalyst, initiator, and ligand were $0.021,0.057$, and $0.057 \mathrm{~g}$, respectively. The mixture was heated at $65^{\circ} \mathrm{C}$ in a silicone oil bath and was refluxed with continuous stirring under argon over $17 \mathrm{~h}$. The reaction mixture was then cooled, and the polymer was precipitated into cyclohexane. The solid was then washed with THF, followed by toluene. Then the solid was dried at $50{ }^{\circ} \mathrm{C}$ in a vacuum oven overnight. For further purification of the polymer, methanol was used to dissolve the polymer and was fractionated by adding toluene into the solution. The polymer was washed by cyclohexane several times and was dried at $50{ }^{\circ} \mathrm{C}$ in a vacuum oven overnight to yield the protected SH-poly(HEMA-g-EG).

In a $20 \mathrm{~mL}$ borosilicate glass scintillation vial, $1 \mathrm{~g}$ of the polymer, $0.6 \mathrm{~g}$ of 2-mercaptoethanol, $0.02 \mathrm{~g}$ of triethylamine, and $0.2 \mathrm{~g}$ of distilled water were added and stirred by a magnetic stirrer at room temperature for $17 \mathrm{~h}$. The solution was then precipitated from toluene and dried in a vacuum oven at $50{ }^{\circ} \mathrm{C}$ overnight. For further purification, methanol was used to dissolve the polymer and was fractionated by adding petroleum ether into the solution. The polymer was separated and dried at $50{ }^{\circ} \mathrm{C}$ in a vacuum oven overnight to yield $\mathrm{SH}$ poly(HEMA-g-EG).

Characterization. ${ }^{1} \mathrm{H}$ NMR spectra were obtained on Varian Inova-501 in chloroform-d or methanol- $\mathrm{d}_{4}$ solvents. Chemical shifts $(\delta)$ were in ppm concentrations downfield from internal TMS reference. GPC spectra were carried out using DAWN from Wyatt Technology, a Waters 510 HPLC pump, and a Waters 410 differential refractometer. The GPC calibration curves for PS, PMMA, and PEG in DMF were then determined using GPC. A BI-200SM light scattering goniometer from Brookhaven Instruments Corp. was used to build Zimm static light scattering pl ots. Different concentrations of the polymer solutions in the range $1-10 \mathrm{mg} / \mathrm{mL}$ in DMF were prepared first and then were filtered using the $5 \mathrm{~mL}$ syringe from Becton Dickinson with the sterilizing $0.22 \mu \mathrm{m}$ filter from Millipore. The calibration was made in toluene. The wavelength of the laser was set at $514 \mathrm{~nm}$, and the measurement angles were in the range $60^{\circ}-130^{\circ}$. The refractive index increments, dn/dc, of the polymers were cal culated on the basis of an equation that assumes that $\mathrm{dn} / \mathrm{dc}$ is an additive function of the composition of a copolymer composing monomers $\mathrm{A}$ and $B, 39$ expressed in terms of weight fraction w which is obtained from ${ }^{1} \mathrm{H} N M R$

$$
\frac{d n}{d c}=w_{A}\left(\frac{d n}{d c}\right)_{A}+w_{B}\left(\frac{d n}{d c}\right)_{B}
$$

dn/dc for PHEMA and PEG in methanol at $25{ }^{\circ} \mathrm{C}$ were
Table 1. Characterization of SH-Poly(HEMA-g-EG)

\begin{tabular}{|c|c|c|}
\hline & $\begin{array}{c}\text { poly(HEMA-g- } \\
\text { EG) } 16 \mathrm{~K}\end{array}$ & $\begin{array}{c}\text { poly(HEMA-g- } \\
\text { EG) } 120 K\end{array}$ \\
\hline \multicolumn{3}{|l|}{${ }^{1} \mathrm{H}$ NMR (methanol- $\mathrm{d}_{4}$ ) } \\
\hline & 16500 & 119700 \\
\hline EG/HEMA (mole ratio) & 0.4 & \\
\hline EG graft density (\%) & & 1.0 \\
\hline $\mathrm{M}_{\mathrm{n}, \mathrm{PHEMA}}$ & 14400 & 103200 \\
\hline $\mathrm{N}_{\text {HEMA }}$ & 111 & 794 \\
\hline $\mathrm{L}_{\text {contour,PHEMA }}(\mathrm{nm})$ & 34.2 & 244.6 \\
\hline $\mathrm{L}_{\text {max,PHEMA }}(\mathrm{nm})$ & 27.9 & 199.5 \\
\hline$M_{n, P E G}$ & 2080 & 16500 \\
\hline$N_{E G}$ & 45 & 360 \\
\hline $\mathrm{L}_{\text {contour,PEG }(\mathrm{nm})}$ & 19.8 & 19.8 \\
\hline $\mathrm{L}_{\text {max }, \mathrm{PEG}}(\mathrm{nm})$ & 16.2 & 16.2 \\
\hline $\mathrm{R}_{\mathrm{g}, \mathrm{PEG}(\mathrm{nm})^{56}}$ & 3.6 & 3.6 \\
\hline \multicolumn{3}{|l|}{$\begin{array}{l}\mathrm{LS}(\mathrm{DMF}) \\
\mathrm{M}_{w}\end{array}$} \\
\hline $\begin{array}{l}M_{w} \\
R_{g}(n m)\end{array}$ & $\begin{array}{l}23400 \\
18.5\end{array}$ & $\begin{array}{l}51300 \\
26.2\end{array}$ \\
\hline \multicolumn{3}{|l|}{ GPC (DMF) } \\
\hline $\mathrm{M}_{\mathrm{w}}$ & 31600 & 104000 \\
\hline$M_{w} / M_{n}$ & 1.3 & 1.2 \\
\hline $\mathrm{C}_{\text {crit }}(\mathrm{mg} / \mathrm{mL})$ & 0.36 & 0.92 \\
\hline$\theta_{\mathrm{a}}\left(\mathrm{deg}, \mathrm{in} \mathrm{H}_{2} \mathrm{O}\right)$ & $89.5 \pm 1.8$ & $89.3 \pm 2.2$ \\
\hline$\theta_{\mathrm{r}}\left(\right.$ deg, in $\left.\mathrm{H}_{2} \mathrm{O}\right)$ & $31.4 \pm 3.5$ & $29.0 \pm 2.9$ \\
\hline
\end{tabular}

calculated to be 0.162 and 0.147 , respectively. dn/dc for poly(HEMA-g-EG) was calculated to be 0.160 . The molecular weight and graft density of the polymer from a ${ }^{1} \mathrm{H} N M R$ spectrum were calculated by comparing the integrals of the protons from the protecting group, PHEMA, and PEG of the poly(HEMA-g-EG). The contour length, $L_{\text {contour, }}$ was calculated for a fully stretched chain using bond lengths of $0.154 \mathrm{~nm}$ for the $\mathrm{C}-\mathrm{C}$ bond and $0.143 \mathrm{~nm}$ for the $\mathrm{C}-\mathrm{O}$ bond, while the maximum possible chain length $L_{\max }$ was calculated using a planar zigzag chain with tetrahedral bond angles of $109.5^{\circ}$.

Preparation of Gold-Coated Silicon Wafers. Polycrystalline gold-coated silicon wafers were prepared by thermal evaporation. The silicon wafers were clipped to a holder which was placed in a vacuum chamber of a diffusion-pumped thermal evaporator. The chamber was pumped to a pressure bel ow $4.0 \times 10^{-6}$ Torr with liquid nitrogen to cool the diffusion pump. Then chromium was evaporated from a resistively heated tungsten boat to the silicon wafer surface at a rate of $0.1 \mathrm{~nm} / \mathrm{s}$ up to the total thickness of $2 \mathrm{~nm}$ to promote adhesion between silicon oxide and gold. I mmediately after gold was evaporated from another resistively heated tungsten boat at a rate of $0.3 \mathrm{~nm} / \mathrm{s}$ up to the total thickness of $50 \mathrm{~nm}$. The thickness was monitored with a quartz crystal oscillator from Inficon.

Preparation of Polymer Mushrooms on Gold-Coated Silicon Wafers. Gold-coated silicon wafers were cleaned by first placing them in a $\mathrm{H}_{2} \mathrm{SO}_{4} / \mathrm{H}_{2} \mathrm{O}_{2}$ (3:1) bath at room temperature for $10 \mathrm{~min}$. The wafers were then extensively rinsed with water and alcohol. Each of them was placed in a vial which was extensively rinsed with water and acetone and then was incubated in a polymer solution for $1 \mathrm{~h}$ at room temperature. The concentration of the polymer solution was kept much lower than the polymer critical concentration, calculated by $^{40}$

$$
C_{\text {crit }}=1.38 \times 10^{-25}\left(\frac{M}{R_{g}{ }^{3}}\right)
$$

where $\mathrm{M}$ is the molecular weight of the polymer $(\mathrm{g} / \mathrm{mol})$ and $\mathrm{R}_{\mathrm{g}}$ the radius of gyration of the polymer $(\mathrm{nm})$. DMF and methanol could be used as solvents, and the concentration for the $16 \mathrm{~K}$ and $120 \mathrm{~K}$ polymers was $0.05 \mathrm{mg} / \mathrm{mL}$, which was much less than their critical concentrations listed in Table 1 . The wafers were then washed with water. The precleaned surfaces were conditioned by successive rinses in methanol, acetone, DMF, methanol, and water. They were then immersed in water or PBS buffer solution to equilibrate for $12 \mathrm{~h}$.

Characterization of Polymer Mushrooms on GoldCoated Silicon Wafers. A N anoScope III A system controller and Multimode (Digital I nstruments) atomi c force microscope 


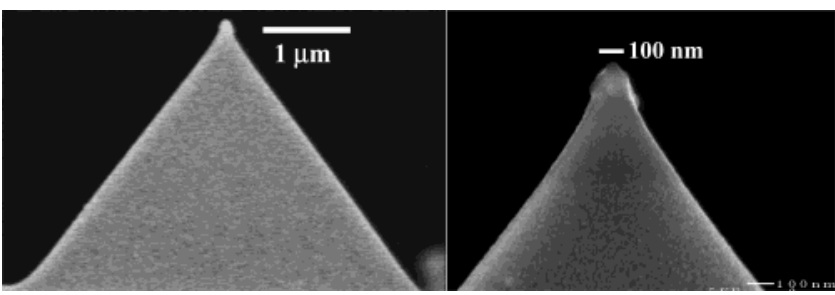

Figure 2. $S E M$ images of the $\mathrm{Si}_{3} \mathrm{~N}_{4}$ probe tip used in the nanomechanical experiments reported in this paper.

(AF M) were used to image the surface of the gold-coated silicon wafers and end-grafted polymer mushroom surfaces. Tapping mode AFM (TMAFM) was used under ambient conditions using the $4197 \mathrm{~J} V$ scanner. The typical scan size, scan rate, scan angle, and image line number were $100-300 \mathrm{~nm}, 4 \mathrm{~Hz}$, $0^{\circ}$, and 512, respectively. Basic parameters optimized to obtain the highest quality of images were the integral gain, proportional gain, amplitude set point, drive frequency, and drive amplitude. The cantilever used was model TESP from Digital Instruments, with cantilever length of $125 \mu \mathrm{m}$, resonant frequency of $200-400 \mathrm{kHz}$, force constant of $20-100 \mathrm{~N} / \mathrm{m}$, and nominal tip radius of curvature of $5-10 \mathrm{~nm}$. The distance between two polymer chains was calculated using the "Section Analysis" command in the image analysis software package of the AFM. A line was drawn between the centers of two nearest-neighbor polymer chains across the image and the 2-dimensional topography mapped along this line. Cursors were then placed on the two points of interest, and the distance between them was recorded. Contact angle measurements were performed using deionized water by a VCA 2000 video contact angle system from ASC.

Single Molecule Force Spectroscopy (SMFS). SMFS experiments were conducted using a new cantilever-based instrument, the Molecular Force Probe (MFP, Asylum Research, Inc) set on a Halcyonics MOD-1 active vibration isolation system, to measure force, $F(n N)$, vs tip-sample separation distance, $D(\mathrm{~nm})$ (henceforth referred to and labeled on graphs as "distance"), on "approach" (i.e., probe tip advancing toward surface) and "retract" (i.e., probe tip moving away from surface). A full description of this instrument, its limits of force and displacement detection in fluids, procedures for spring constant calibration and conversion of raw data, details of measurement errors, and description of typical force vs distance curves including the mechanical instabilities of the cantilever, are given in our previous work. ${ }^{41,42}$ Force $(\mathrm{nN})$ vs distance $(\mathrm{nm})$ curves were measured at room temperature using Thermomicroscopes microfabricated V-shaped $\mathrm{Si}_{3} \mathrm{~N}_{4}$ cantilevers with the square-pyramidal probe tip. The cantilevers were with the fol lowing dimensions: cantilever length of $320 \mu \mathrm{m}$, cantilever width of $22 \mu \mathrm{m}$, cantilever thickness of 0.6 $u \mathrm{~m}$, force constant of $0.01 \mathrm{~N} / \mathrm{m}$, and resonant frequency of 7 $\mathrm{kHz}$. The cantilevers were at a constant z-piezo displacement rate $=1 \mu \mathrm{m} / \mathrm{s}$ reversing immediately between approach and retract cycles (no dwell time on the surface), z-piezo range $=$ $1 \mu \mathrm{m}$ (slow enough to minimize hydrodynamic effects), and rate of data acquisition $=4000$ points/s, in PBS solution or deionized water. On approach, nanomechanical data were averaged over many experiments and presented always with standard deviations and normalized by the end probe tip radius, $\mathrm{R}_{\mathrm{TIP}}$, giving a representative effective energy of interaction. On retract, the adhesive forces and distances were analyzed statistically.

$\mathrm{R}_{\text {TIP }}$ for the probe tip used for nanomechanical testing was measured via SEM (Figure 2) using a J EOL 6320 SE M with an operating voltage of $5 \mathrm{kV}$ and magnitude of $64000 \times . R_{\mathrm{TIP}}$ was calculated by eq 3

$$
R_{T I P}=\frac{d / 2}{\sin \left(90^{\circ}-\alpha\right)}
$$

where $\alpha\left(=35^{\circ}\right)$ was the tip half angle and $d$ was the distance between two points of tangency obtained by two side lines of the triangle tip image tangential to the tip end, which was measured directly by SEM. $R_{\text {TIP }}$ was found to be equal to $\sim 26$ $\mathrm{nm}$ for the probe tip employed in this study.

\section{Results}

Initiator and Polymer Characterization. The ATRP method using DPEBM initiator was used to prepare protected thiol-terminated poly(HEMA-g-EG), and then the end-protecting group was removed with mercaptoethanol. The success of the synthesis was verified by ${ }^{1} \mathrm{H}$ NMR with the DPEBM intermediate 2-(2,4-dinitrophenylthio)ethanol (chloroform-d, $\delta$ ): 9.09$9.08(\mathrm{~d}, 1 \mathrm{H}, \mathrm{J}=2.5 \mathrm{~Hz}), 8.40-8.37\left(\mathrm{dd}, 1 \mathrm{H}, \mathrm{J}_{1}=2.6\right.$ $\mathrm{J} 2=8.9 \mathrm{~Hz}), 7.71-7.68(\mathrm{~d}, 1 \mathrm{H}, \mathrm{J}=9.1 \mathrm{~Hz}), 4.08-4.02$ $(q, 2 \mathrm{H}, \mathrm{J}=5.9 \mathrm{~Hz}), 3.34-3.30(\mathrm{t}, 2 \mathrm{H}, \mathrm{J}=6.1 \mathrm{~Hz}), 1.89$ $(\mathrm{t}, 1 \mathrm{H}, \mathrm{J}=5.6 \mathrm{~Hz}$ ), and the DPEBM initiator (dhloroformd, $\delta$ ): $9.12-9.11(\mathrm{~d}, 1 \mathrm{H}, \mathrm{J}=2.5 \mathrm{~Hz}), 8.49-8.45(\mathrm{dd}, 1 \mathrm{H}$, $\left.\mathrm{J}_{1}=2.5, \mathrm{~J}_{2}=9.1 \mathrm{~Hz}\right), 7.85-7.82(\mathrm{~d}, 1 \mathrm{H}, \mathrm{J}=8.8 \mathrm{~Hz})$, $4.50-4.46(\mathrm{t}, 2 \mathrm{H}, \mathrm{J}=6.0 \mathrm{~Hz}), 3.43-3.38(\mathrm{t}, 2 \mathrm{H}, \mathrm{J}=6.0$ $\mathrm{Hz})$, and $1.96(\mathrm{~s}, 6 \mathrm{H})$. Figure 3a shows the ${ }^{1} \mathrm{H}$ NMR spectrum for the protected SH-poly(HEMA-g-EG) ${ }_{16 \mathrm{~K}}$ in methanol- $\mathrm{d}_{4}$ with peaks at $\delta 9.08,8.54$, and 8.03 with equivalent integrated areas that were attributed to the protons at positions 1, 2, and 3 (chemical structure shown as inset of Figure 3a) from the 2,4-dinitrophenyl protecting group. The peaks at $\delta 4.05$ and 3.79 were attributed to the protons at positions 4 and 5, respectively, from the backbone of PHEMA, and the peak at $\delta 3.65$ was attributed to the protons at positions 6 and 7 from the PEG graft side chains. Once the protecting group was removed with mercaptoethanol, the characteristic end group peaks at positions 1, 2, and 3 vanished as shown in Figure $3 \mathrm{~b}$.

As shown in Table 1 , the ${ }^{1} \mathrm{H}$ NMR spectra were also employed to provide further information including the PEG side chain graft density and the molecular weight of the polymers. The graft density of PEG to PHEMA was obtained by the ratio of the integrated area at peaks 6 and 7 to the integrated area at peaks 4 or 5 . By setting the integrated area at peak 1,2, or 3 as a unit, the integrated area at peak 4 or 5 could give half of the number of 2-hydroxyethyl groups. Thus, the corre sponding molecular weight of the backbone of the polymer could be obtained. This combined with the graft density could give the total molecular weight of the polymer (Table 1). From these MWs, the HEMA polymer contour lengths, $\mathrm{L}_{\text {contour, }}$ were calculated as detailed in the Experimental Section to be $\sim 34$ and $\sim 245 \mathrm{~nm}$ for the $16 \mathrm{~K}$ and $120 \mathrm{~K}$ MWs, respectively, and the PEG $\mathrm{L}_{\text {contour }}$ was $\sim 20 \mathrm{~nm}$. Figure 4 is a schematic summarizing these data of the sizes of the polymers synthesized drawn approximately to scale based on ${ }^{1} \mathrm{H}$ NMR data. Figure 5 shows the light scattering Zimm plot of $\mathrm{SH}$ poly(HEMA-g-EG) 120K $_{2}$ in DMF. Since no standard poly(HEMA-g-EG) was available, the MWs obtained by NMR should be more accurate.

Characterization of End-Grafted Polymer Mushrooms on Gold-Coated Silicon Wafers by AFM. TMAFM was applied to characterize the bare goldcoated silicon wafer surfaces (Figure $6 a$ ) and the gold substrates that had been end-grafted with poly(HEMA$\mathrm{g}-\mathrm{E} G$ ) (Figure $6 \mathrm{~b}, \mathrm{c}$ ). The gold root-mean-square surface roughness, island size, and island peak-to-valley height were found to be $\sim 1.2 \mathrm{~nm}, 32.4 \pm 3.7 \mathrm{~nm}$, and $2.0 \pm 0.6$ $\mathrm{nm}$, respectively. The raised white, globular spots on top of the gold substrate in Figure $6 b, c$ were attributed to individual separated poly(HEMA-g-EG) chains. As shown in Figure $6 \mathrm{~b}$, the end-grafted polymers were 


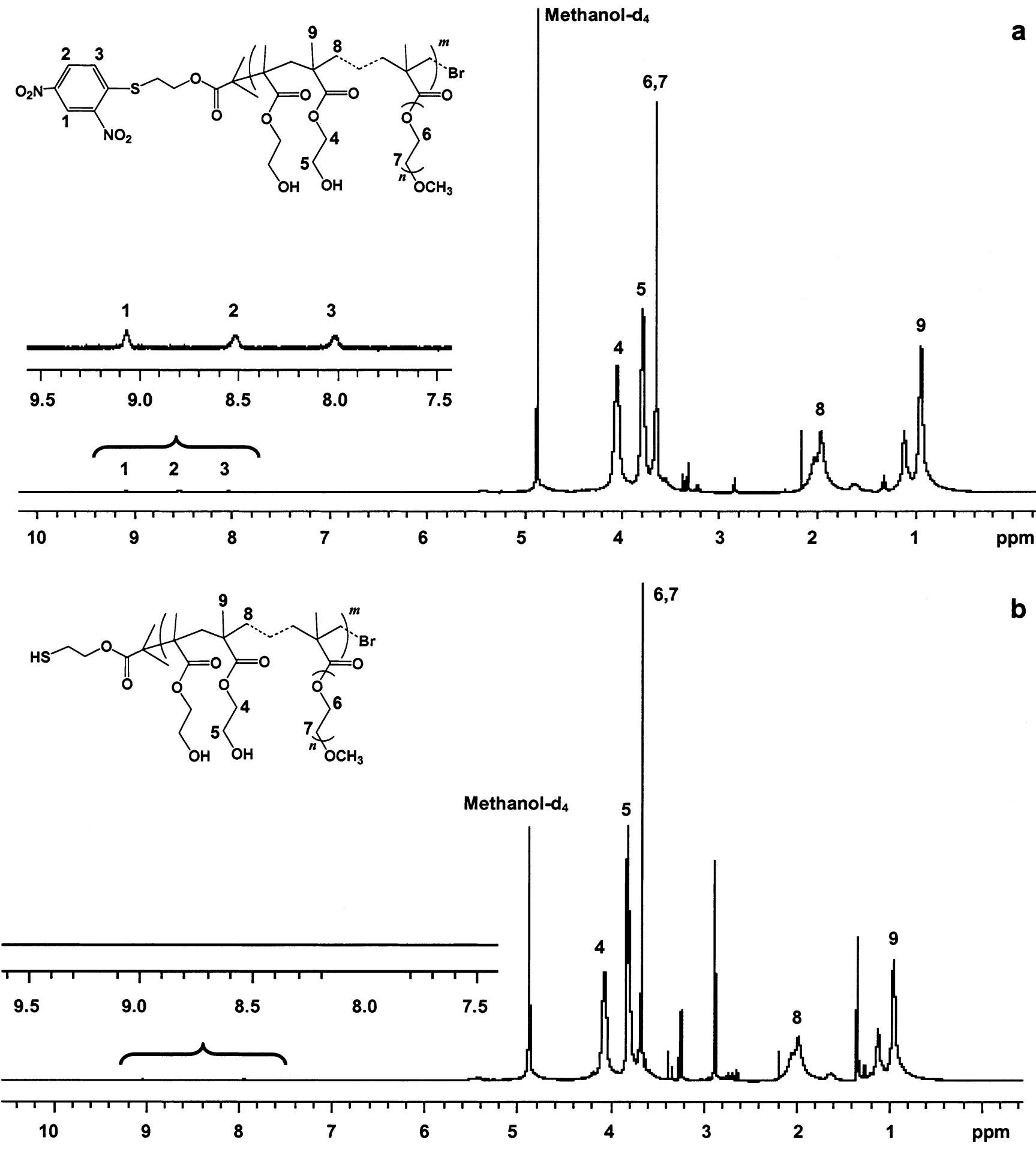

Figure 3. ${ }^{1 H}$ NMR spectra in methanol-d $d_{4}$ of protected SH-poly(HEMA-g-EG) ${ }_{16 K}(a)$ and SH-poly(HEMA-g-EG) $)_{16 K}(b)$.

found to be exhibit a wide variety of conformations, including collapsed and expanded spherical coils and partially to fully extended wormlike conformations. This broad distribution of conformations observed is most likely due to deformation of the polymer chains by compressive and lateral forces applied by the probe tip during imaging and polymer-substrate intermol ecular interactions (e.g., hydrophobic interactions). The distance between neighboring polymer chains, $\mathrm{s}$, was measured to be $33.4 \pm 6.5$ and $71.8 \pm 9.0 \mathrm{~nm}$ for the $16 \mathrm{~K}$ and $120 \mathrm{~K}$ polymers, respectively. For the $16 \mathrm{~K}$ polymer, the height was found to be $1.0 \pm 0.4 \mathrm{~nm}$, and the maximum polymer dimension was measured to be $12.5 \pm 10.3 \mathrm{~nm}$. For the $120 \mathrm{~K}$ polymer the height was found to be $2.3 \pm 0.6 \mathrm{~nm}$, and the maximum polymer dimension was $30.2 \pm 8.2 \mathrm{~nm}$. The heights are quite small since the polymer chains are unavoidably compressed and dragged laterally by the probe tip during imaging.

Advancing contact angle $\left(\theta_{\mathrm{a}}\right)$ and receding contact angle $\left(\theta_{r}\right)$ measurements for the end-grafted poly(HEMA-g-EG) mushroom gold substrates in DI water are listed in Table 1 and were $\sim 89 \pm 2^{\circ}$ and $\sim 30 \pm 3^{\circ}$, respectively, for both MW polymers. As a control, $\theta_{\mathrm{a}}$ and $\theta_{\mathrm{r}}$ for the bare gold-coated silicon wafer surfaces were $85.7 \pm 0.7^{\circ}$ and $57.1 \pm 2.1^{\circ}$, respectively.

Nanoscale Surface Interactions of End-Grafted Poly(HE MA-g-E G)Mushrooms on Approach. Parts 


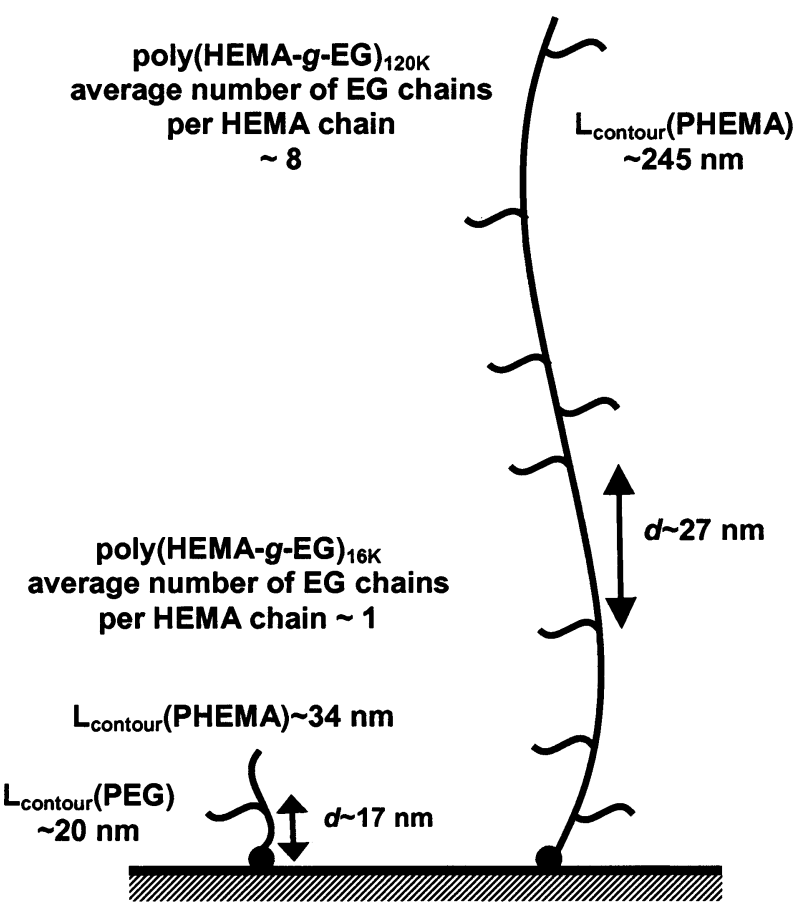

Figure 4. Schematic of sizes of polymers synthesized drawn approximately to scale.

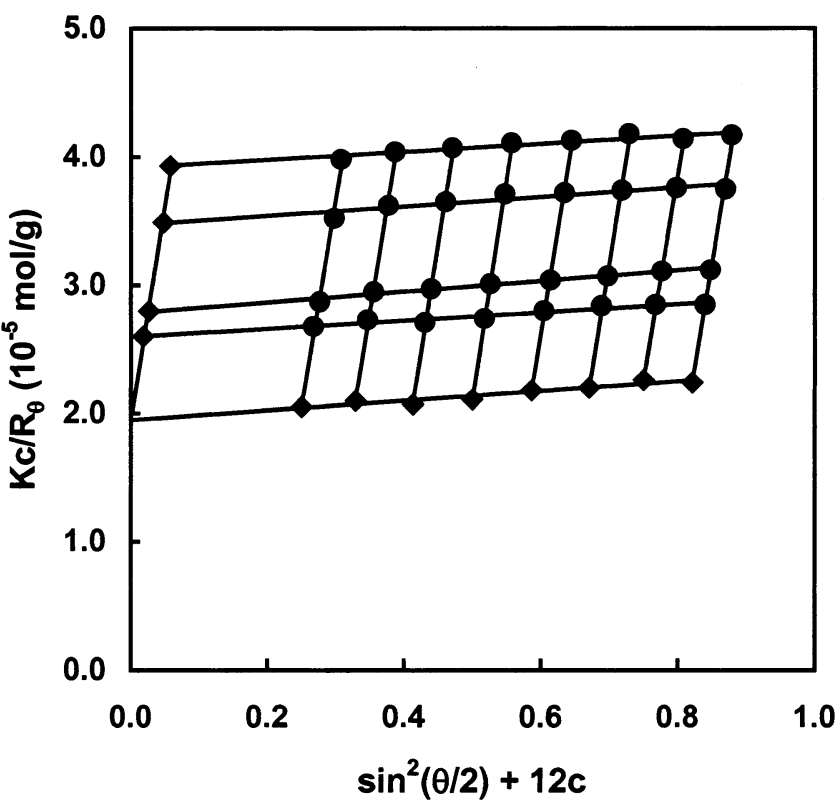

Figure 5. LS Zimm plot of SH-poly(HEMA-g-EG) ${ }_{120 \mathrm{~K}}$ in DMF.

$a$ and $b$ of Figure 7 show average approach force $(\mathrm{pN})$ and force/radius ( $\mathrm{mN} / \mathrm{m}$ ) vs distance $(\mathrm{nm})$ curves, along with standard deviations, between $\mathrm{a} \mathrm{Si}_{3} \mathrm{~N}_{4}$ probe tip and an $\mathrm{Au}$ substrate end-grafted with poly(HEMA-g-EG) $16 \mathrm{~K}$ and $120 \mathrm{~K}$ mushrooms, respectively, in $\mathrm{H}_{2} \mathrm{O}(\boldsymbol{\bullet})$ and PBS (O). As shown in Figure 7a, the poly(HEMA-g$E G)_{16 \mathrm{~K}}$ in water exhibited a long-range, purely repulsive force starting at $D_{\max } \sim 40 \mathrm{~nm}$ and reaching a maximum magnitude of $\sim 33 \mathrm{pN}$, corresponding to a force/radius $\sim 1.22 \mathrm{mN} / \mathrm{m}$ at $\mathrm{D} \sim 3 \mathrm{~nm}$. For $\mathrm{D}<3 \mathrm{~nm}$, a drop in the force with decreasing distance occurs due to attractive surface interactions until reaching the constant compliance regime at $\mathrm{D}=0$. An interesting force sign reversal is observed when the nanomechanical experiments are carried out in PBS, and the interaction becomes purely attractive for $D_{\max }<10 \mathrm{~nm}$ reaching a maximum a

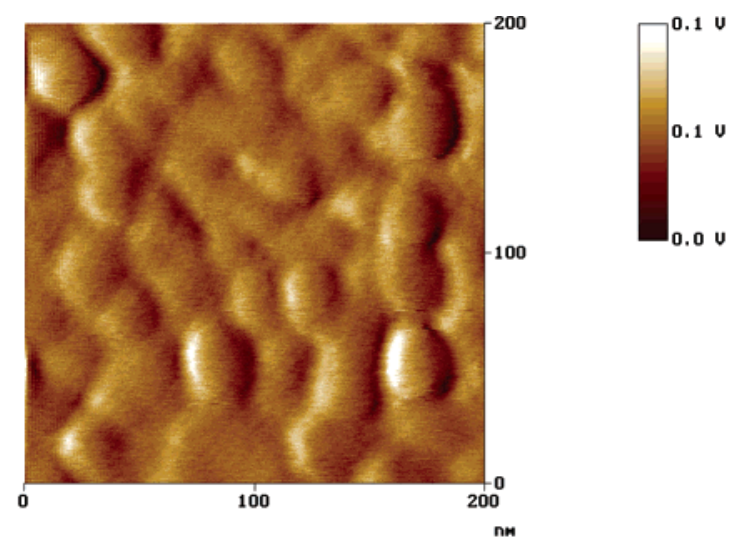

b

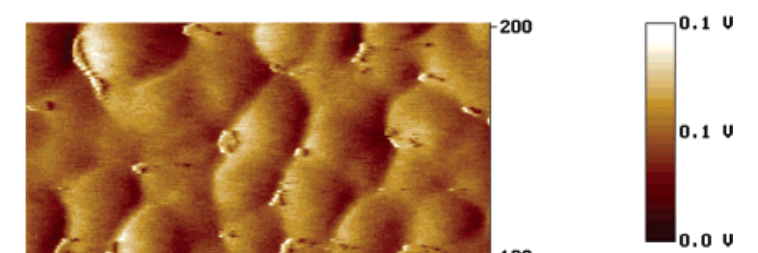

C

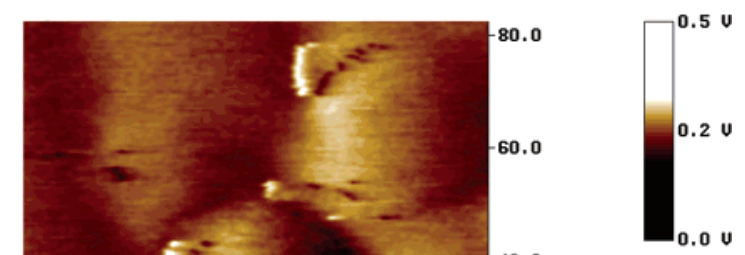

Figure 6. Tapping mode AFM amplitude images in air of bare $\mathrm{Au}(\mathrm{a})$ and end-grafted mushrooms of poly(HEMA-g-EG) ${ }_{16 \mathrm{~K}}$ on Au: $200 \mathrm{~nm}$ scan (b) and $85 \mathrm{~nm}$ scan (c).

average value of $\sim-5 \mathrm{pN}$, corresponding to a force/ radius of $\sim-0.2 \mathrm{mN} / \mathrm{m}$ at a distance of $\sim 3 \mathrm{~nm}$. As shown in Figure 7b, the poly(HEMA-g-EG) ${ }_{120 K}$ exhibited similar behavior compared to the poly(HEMA-g-EG) ${ }_{16 \mathrm{~K}}$, including a long-range, purely repul sive force for $D_{\max }$ $<\sim 40 \mathrm{~nm}$ reaching a larger maximum magnitude of $\sim 61 \mathrm{pN}$, corresponding to a force/radius $\sim 2.3 \mathrm{mN} / \mathrm{m}$ at $D \sim 3 \mathrm{~nm}$. In PBS, the range of the interaction dropped significantly to $D_{\max }<4.5 \mathrm{~nm}$ but still remained repulsive reaching a maximum magnitude of $\sim 20 \mathrm{pN}$, corresponding to a force/radius of $\sim 0.07 \mathrm{mN} / \mathrm{m}$.

The relevant approach parameters were calculated as described previously ${ }^{43}$ and are summarized in Table 2 . The approximate number of polymer chains present in the maximum projected surface interaction area at $D$ $=0$ was found to be $<1.9$ (based on the probe tip radius and polymer grafting density measured by AFM imaging), and the polymer chains covered $<14 \%$ of the total 

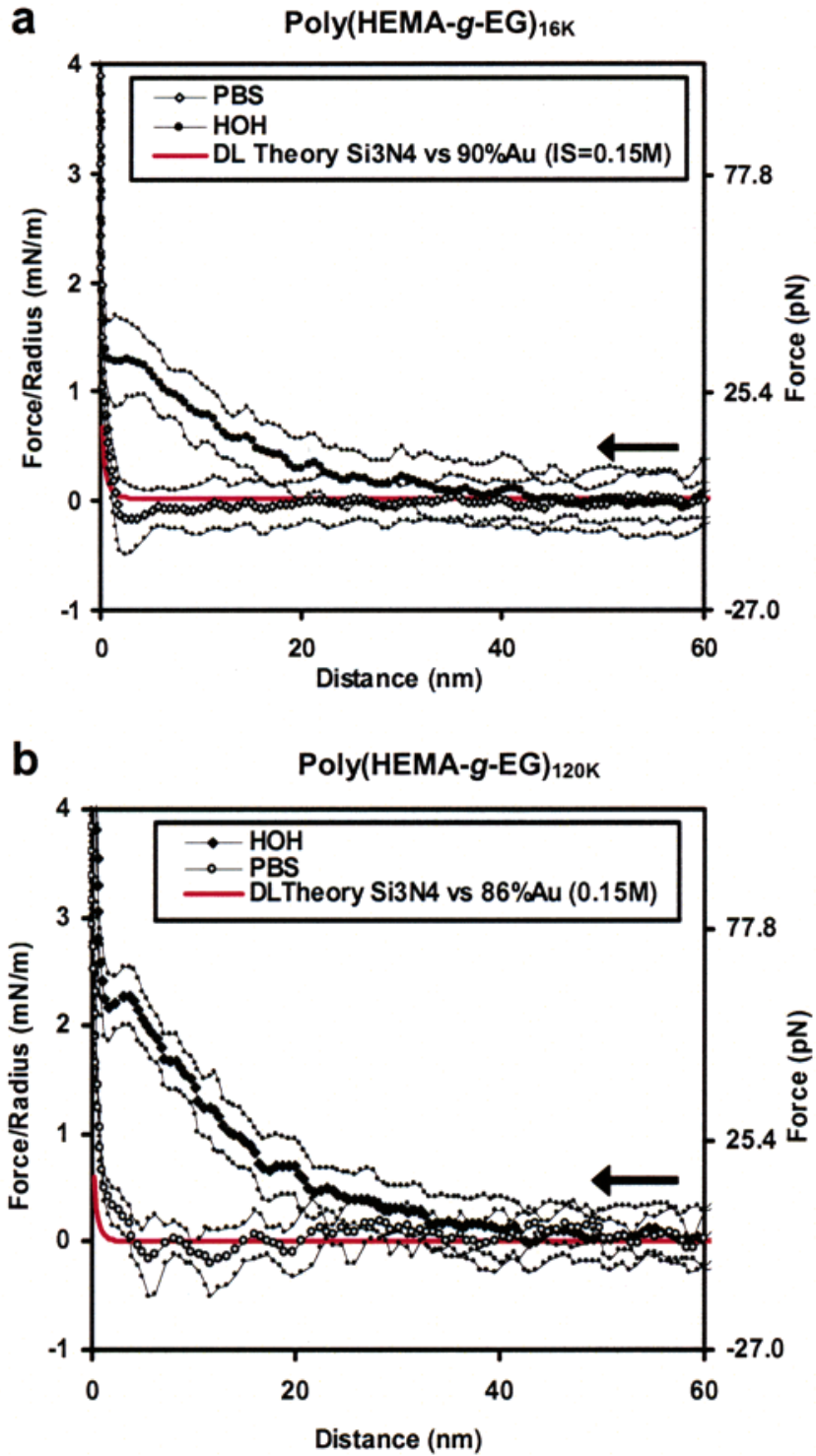

Figure 7. Average force $(\mathrm{nN})$ and force/radius $(\mathrm{mN} / \mathrm{m})$ vs distance $(\mathrm{nm})$ curves on approach between $\mathrm{Si}_{3} \mathrm{~N}_{4}$ probetip and end-grafted poly(HEMA-g-EG) ${ }_{16 K}$ (a) and poly(HEMA-g-EG) $)_{120 K}$ (b) on $\mathrm{Au}$ in PBS (O) and $\mathrm{DI} \mathrm{H}_{2} \mathrm{O}()^{\circ}$; smaller symbols represent standard deviations and solid red lines represent EDL theoretical simulations.

surface area while the remaining $>86 \%$ was bare Au (calculated on the basis of the largest polymer dimension measured by AFM imaging). Previously, we approximated the net approach surface interaction of polymer mushrooms end-grafted on $\mathrm{Au}$ as a linear addition of the polymer and Au interactions taken separately. ${ }^{44}$ The bare polycrystalline Au used in this study has been found previousl $y^{43}$ to have a net negative charge under these solution conditions due to adsorbed anions with a surface charge per unit area of $\sigma(\mathrm{Au})=0.0144 \mathrm{C} / \mathrm{m}^{2}$, and the $\mathrm{Si}_{3} \mathrm{~N}_{4}$ probetip is known ${ }^{45-47}$ to also have a net negative charge due to ionized silanol $\left(\mathrm{SiO}^{-}\right)$and silylamine $\left(\mathrm{SiN}^{-}\right.$) groups of $\sigma\left(\mathrm{Si}_{3} \mathrm{~N}_{4}\right)=-0.032 \mathrm{C} / \mathrm{m}^{2}$, yielding an electrostatic double-layer (EDL) repulsion with an electrical interaction Debye length (calculated from the solution IS $=0.15 \mathrm{M}), \kappa^{-1}$ of $\sim 1 \mathrm{~nm}$ in PBS and $\sim 39 \mathrm{~nm}$ in $\mathrm{DI} \mathrm{H}_{2} \mathrm{O} .48$ The EDL repulsion solely due to the $\mathrm{Si}_{3} \mathrm{~N}_{4}$ vs Au interaction in PBS (i.e., for $90 \%$ and $86 \%$ of total surface area for the poly(HEMA-g-EG) $)_{16 K}$ and poly(HEMA-g-EG) ${ }_{120 K}$ samples, respectively) was
Table 2. Relevant Parameters for Approach Nanomechanical Data ${ }^{a}$

\begin{tabular}{|c|c|c|}
\hline sample & $\begin{array}{c}\text { poly(HEMA-g- } \\
\text { EG) }{ }_{16 K}\end{array}$ & $\begin{array}{c}\text { poly(HEMA-g- } \\
\text { EG) })_{120 \mathrm{~K}}\end{array}$ \\
\hline \multicolumn{3}{|c|}{ Solvent $=$ PBS } \\
\hline$A_{\text {substrate }}\left(\mathrm{nm}^{2}\right)$ & 1320 & 1320 \\
\hline $\mathrm{s}(\mathrm{nm})$ & 33 & \\
\hline $\begin{array}{l}\text { area per polymer chain } \\
\text { including } \mathrm{Au}, \mathrm{s}^{2}\left(\mathrm{~nm}^{2}\right)\end{array}$ & 1089 & 5184 \\
\hline no. polymer chains in $A_{\text {substrate }}$ & 1.3 & 0.27 \\
\hline A polymer $\left(\mathrm{nm}^{2}\right)$ & 110 & 700 \\
\hline $\begin{array}{l}\% \text { of surface area taken up by } \\
\text { polymer }\end{array}$ & 10 & 14 \\
\hline \multicolumn{3}{|c|}{ Solvent $=$ DI Water } \\
\hline$A_{\text {substrate }}\left(\mathrm{nm}^{2}\right)$ & 2123 & 2123 \\
\hline $\mathrm{s}(\mathrm{nm})$ & 33 & \\
\hline $\begin{array}{l}\text { area per polymer chain } \\
\text { including } A u, s^{2}\left(\mathrm{~nm}^{2}\right)\end{array}$ & 1089 & 5184 \\
\hline no. polymer chains in $A_{\text {substrate }}$ & 1.9 & 0.41 \\
\hline$A_{\text {polymer }}\left(\mathrm{nm}^{2}\right)$ & 110 & 700 \\
\hline $\begin{array}{l}\% \text { of surface area taken up by } \\
\text { polymer }\end{array}$ & 10 & 14 \\
\hline
\end{tabular}

a $A_{\text {substrate }}$ is the approximate maximum projected substrate interaction area. For the experiments conducted in $\mathrm{HOH}$ a maximum interaction distance of $D=27 \mathrm{~nm}$ was employed due to the fact that this calculation is only valid for $D<R_{\text {tip }}{ }^{43}$ Hence, $A_{\text {substrate }}$ is expected to be slightly underestimated. A polymer is the approximate area taken up by a single polymer chain as calculated from the measured dimensions by AFM imaging.

model ed using a constant surface charge approximation based on the numerical solution to the nonlinear Poisson-Boltzmann (PB) equation including divalent ions, ${ }^{49-51}$ and these simulated curves are shown in Figure 8 as solid lines. The $\mathrm{Si}_{3} \mathrm{~N}_{4}$ vs Au EDL interaction in $\mathrm{H}_{2} \mathrm{O}$ was not presented here due to the fact that the hemispherical probe tip approximation used to approximate the actual probe tip geometry ${ }^{52}$ is expected to greatly underestimate the magnitude of the force for $\mathrm{R}_{\text {TIP }} \sim 27 \mathrm{~nm}$ and interactions that take place up to $5 \kappa^{-1}$ $=195 \mathrm{~nm}$; i.e., much more surface area up the pyramidal sides of the probe tip will contribute to the force and is not taken into account by the approximation.

Nanomechanical Properties of End-Grafted Poly(HEMA-g-E G)Mushrooms on Retract. When the $\mathrm{Si}_{3} \mathrm{~N}_{4}$ probe tip was retracted away from the poly(HEMA-g-E G) substrates, it almost always exhibited a small, short-range pull-off due to surface adhesion. A small percentage of the total force curves for all four data sets $(<2 \%)$ showed an individual attractive peak in which the magnitude of the force increased nonlinearly with distance while the majority of the rest ( 98\%) did not exhibit any long-range interaction. These attractive peaks were attributed to the stretching of an individual polymer chain where some chain segments had become physically adsorbed to the probe tip on approach and act as a tether enabling bridging and extension of the polymer chain between the substrate and tip. Such typical single macromolecule elasticity force profiles are given in Figure 8, which shows individual approach and retract force $(\mathrm{nN})$ and force/ fadius $(\mathrm{mN} / \mathrm{m})$ vs distance $(\mathrm{nm})$ curves between the $\mathrm{Si}_{3} \mathrm{~N}_{4}$ probe tip and an Au substrate end-grafted with poly(HEMA-g-EG) mushrooms in $\mathrm{H}_{2} \mathrm{O}$ and PBS.

At high enough extensions, the elastic restoring force of the chain becomes equal to and just exceeds the physisorption force tethering the chain segments to the tip and the tethered chain segments detach from the probe tip. Upon detachment, the cantilever exhibits a mechanical instability and is returned back to its 

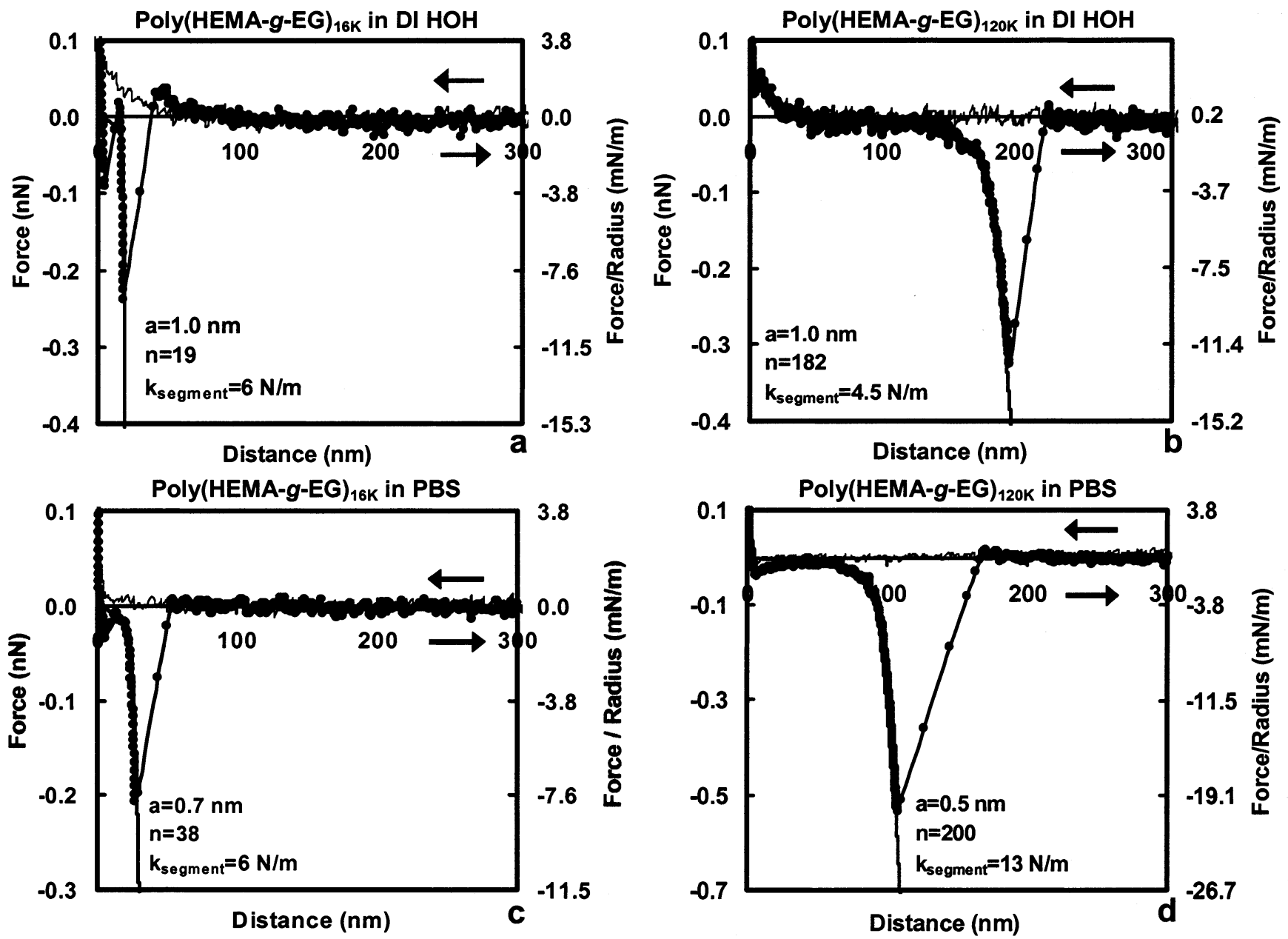

Figure 8. Individual force $(\mathrm{nN})$ and force/radius $(\mathrm{mN} / \mathrm{m})$ vs distance $(\mathrm{nm})$ curves on approach (thin black lines) and retract (thick black lines) using a $\mathrm{Si}_{3} \mathrm{~N}_{4}$ probe tip showing extension of a single chain of (a) poly(HEMA-g-EG) $16 \mathrm{~K}$ in DI $\mathrm{H}_{2} \mathrm{O}$, (b) poly$(\mathrm{HEMA}-\mathrm{g}-\mathrm{EG})_{120 \mathrm{~K}}$ in $\mathrm{DI} \mathrm{H}_{2} \mathrm{O}$, (c) poly(HEMA-g-EG) $16 \mathrm{~K}$ in PBS, and (d) poly(HEMA-g-EG) $)_{120 \mathrm{~K}}$ in PBS all fitted to the extensible FJ C model (solid lines).

undeflected position corresponding to zero force. By comparing the poly(HEMA-g-EG) $)_{16 K}$ (Figure 8a,c) to the poly(HEMA-g-EG) $120 \mathrm{~K}$ (Figure 8b,d), one can immediately see that, as expected, the extensional distances were significantly greater for the higher MW polymer (a full statistical analysis of these distances will be presented in the following section) and consistent with the contour lengths estimated from the known molecular weights (Table 1 ). A minute percentage $(0.03 \%)$ of the total force curves exhibited multiple peaks on retract as shown in Figure 9.

The solid lines shown in the plots in Figure 8 and similar SMFS data were fits using the extensible freely jointed chain model (extFJ C) ) $^{53}$ which takes into account configurational entropy as well as high strain enthalpic extension of the statistical segments. The text insets in the plots of Figure 8 give the three extFJ C fitting parameters used for those particular fits in the corresponding graph; i.e., a is the statistical segment (Kuhn) length and reflects the resistance to bending of the polymer backbone which dominates entropic elasticity in the low-to-intermediate strain regime, $\mathrm{k}_{\text {segment }}$ is the statistical segment elasticity which reflects the resistance of the polymer chain backbone to extensional deformations and contributes to the total molecular elasticity profile via enthalpic disruptions of supramolecular structure in the intermediate to high strain regime, and $\mathrm{n}$ is the number of statistical segments. The

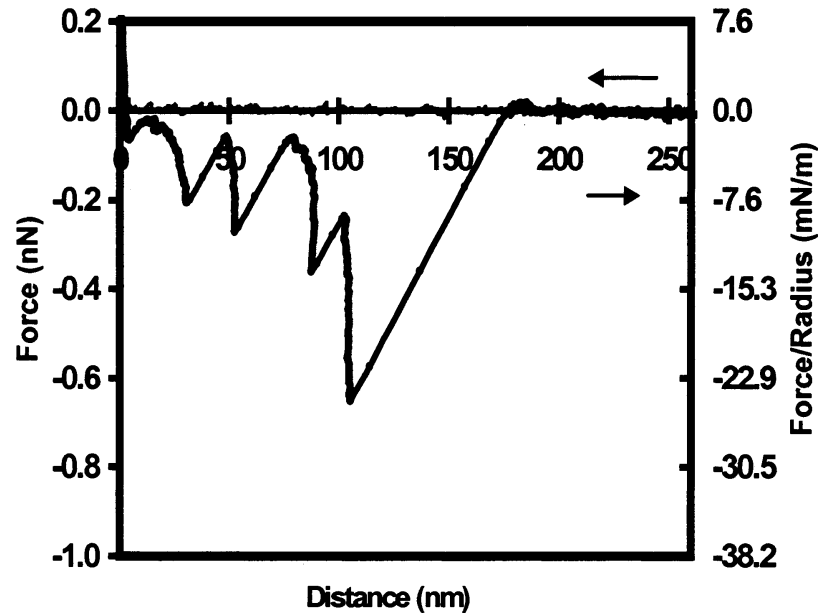

Figure 9. The $0.03 \%$ of total force curves exhibited a force vs distance curve with multiple attractive peaks on retract similar to that shown here for poly(HEMA-g-EG) ${ }_{120 \mathrm{~K}}$ in PBS.

two parameters that represent the physical nanoscale properties of the chain (a and $\mathrm{k}_{\text {segment }}$ ) are independent of the MW or length of the bridging chain segment. The extFJ C model fits for the poly(HEMA-g-EG) ${ }_{120 \mathrm{~K}}$ single molecule elasticity peaks yielded $a=0.52 \pm 0.09 \mathrm{~nm}$, $\mathrm{k}_{\text {segment }}=10.5 \pm 3.3 \mathrm{~N} / \mathrm{m}$ in PBS and $\mathrm{a}=1.03 \pm 0.01$ $\mathrm{nm}, \mathrm{k}_{\text {segment }}=4.2 \pm 0.5 \mathrm{~N} / \mathrm{m}$ for the $\mathrm{H}_{2} \mathrm{O}$. The poly- 

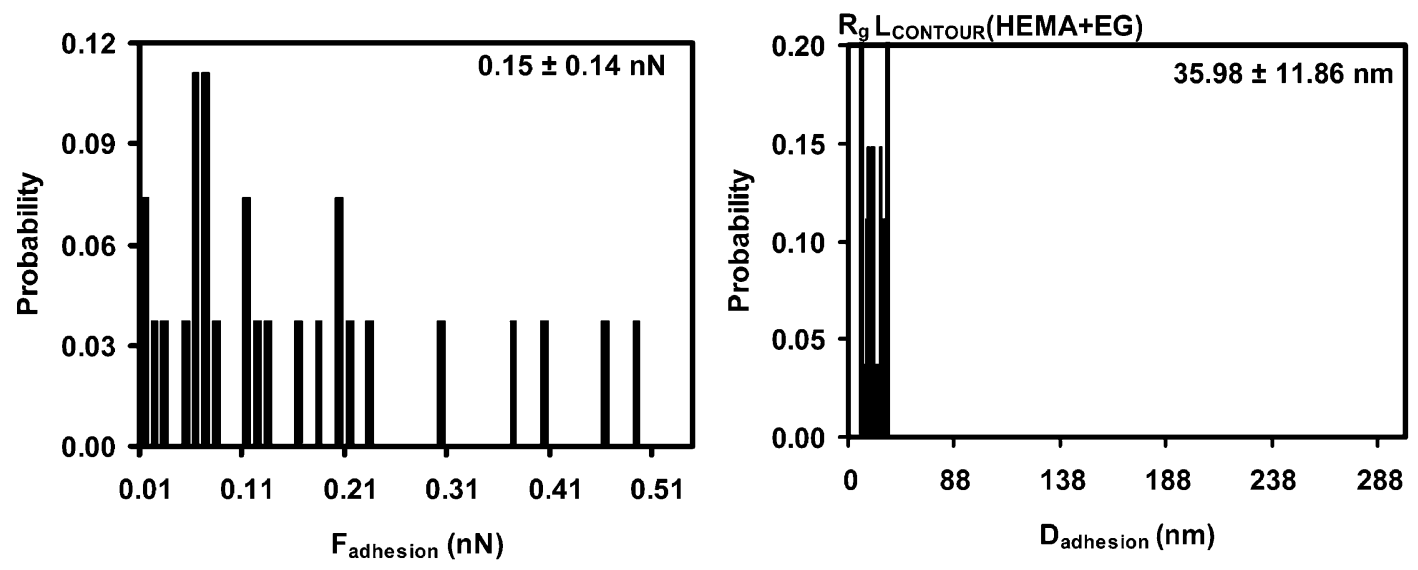

b
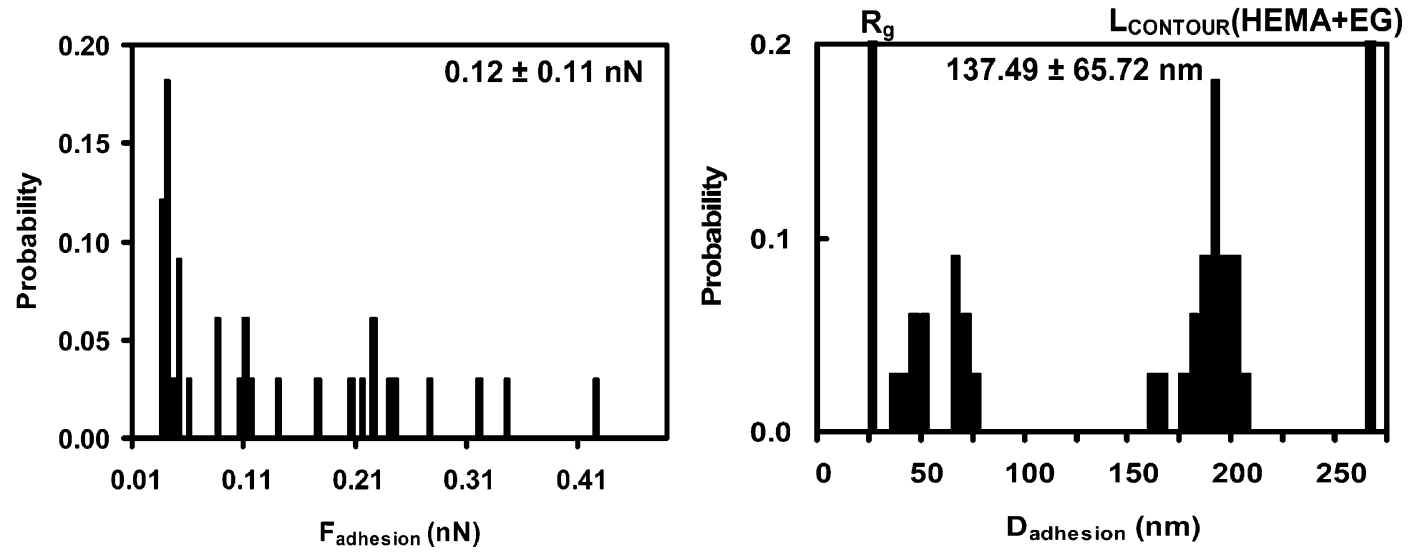

Figure 10. Probability distributions of single molecule detachment forces and distances for (a) poly(HEMA-g-EG) ${ }_{16 k}$ and (b) poly(HEMA-g-EG) ${ }_{120 \mathrm{~K}}$ in $\mathrm{DI} \mathrm{H}_{2} \mathrm{O}$. Inset numerical values are the calculated mean and standard deviation for that dataset.

Table 3. Statistical Analysis of Adhesion Data on Retract ${ }^{\mathrm{a}}$

\begin{tabular}{lll}
\hline \multicolumn{1}{c}{ sample } & $\begin{array}{c}\text { poly(HEMA-g- } \\
\text { EG) })_{16 \mathrm{~K}}\end{array}$ & $\begin{array}{c}\text { poly(HEMA-g- } \\
\mathrm{EG})_{120 \mathrm{~K}}\end{array}$ \\
\hline solvent $=\mathrm{PBS}$ & $\mathrm{n}=30,1.3 \%$ of & $\mathrm{n}=41,1.3 \%$ of \\
& data & data \\
$\left\langle\mathrm{F}_{\text {adhesion }}\right\rangle(\mathrm{nN})$ & $0.39 \pm 0.18$ & $0.16 \pm 0.13$ \\
$\left\langle\mathrm{~F}_{\text {adhesion }} / \mathrm{R}_{\text {tip }}\right\rangle(\mathrm{mN} / \mathrm{m})$ & $15.04 \pm 6.95$ & $6.14 \pm 4.99$ \\
$\left\langle\mathrm{D}_{\text {adhesion }}\right\rangle(\mathrm{nm})$ & $42.31 \pm 6.64$ & $77.17 \pm 27.79$ \\
a $(\mathrm{nm})$ & & $0.52 \pm 0.09$ \\
$\mathrm{k}_{\text {segment }}(\mathrm{N} / \mathrm{m})$ & & $10.5 \pm 3.3$ \\
solvent $=\mathrm{DI}$ water & $\mathrm{n}=27,2.1 \%$ of & $\mathrm{n}=33,8.7 \%$ of \\
& data & data \\
$\left\langle\mathrm{F}_{\text {adhesion }}\right\rangle(\mathrm{nN})$ & $0.15 \pm 0.14$ & $0.12 \pm 0.11$ \\
$\left\langle\mathrm{~F}_{\text {adhesion }} / \mathrm{R}_{\text {tip }}\right\rangle(\mathrm{mN} / \mathrm{m})$ & $5.83 \pm 5.25$ & $4.67 \pm 4.11$ \\
$\left\langle\mathrm{D}_{\text {adhesion }}\right\rangle(\mathrm{nm})$ & $35.98 \pm 11.86$ & $137.49 \pm 65.72$ \\
a $(\mathrm{nm})$ & & $1.03 \pm 0.01$ \\
$\mathrm{k}_{\text {segment }}(\mathrm{N} / \mathrm{m})$ & & $4.2 \pm 0.5$
\end{tabular}

a $\mathrm{n}$ is the number of force curves with single molecule peaks used in the calculation.

(HEMA-g-EG) ${ }_{16 \mathrm{~K}}$ single molecule elasticity peaks were generally too short to produce reasonably accurate estimates of the fitting parameters.

Adhesion Probability Distributions between $\mathrm{Si}_{3} \mathrm{~N}_{4}$ Probe Tip and End-Grafted Poly(HEMA-gEG) Mushrooms on Retract. The probability distributions of the single molecule poly(HEMA-g-EG) detachment or desorption forces from the probe tip, $\mathrm{F}_{\text {adhesion, }}$ and corresponding distances, $\mathrm{D}_{\text {adhesion, on }} \mathrm{re}$ tract in $\mathrm{H}_{2} \mathrm{O}$ are shown in Figure 10 and Table 3. The mean values were as follows: $\left\langle F_{\text {adhesion }}\right\rangle=0.15 \pm 0.14$
$\mathrm{nN}$ and $\left\langle\mathrm{D}_{\text {adhesion }}\right\rangle=35.98 \pm 11.86 \mathrm{~nm}$ for the $16 \mathrm{~K}$ and $\left\langle\mathrm{F}_{\text {adhesion }}\right\rangle=0.12 \pm 0.11 \mathrm{nN}$ and $\left\langle\mathrm{D}_{\text {adhesion }}\right\rangle=137.49 \pm$ $64.72 \mathrm{~nm}$ for the $120 \mathrm{~K}$. The distance distributions were generally less than $L_{\text {contour }}$ calculated from the known $M W$ and greater than the known $R_{g}$ measured by LS in DMF (shown as vertical solid bars in Figure 10). An interesting distinct separation of the distribution of

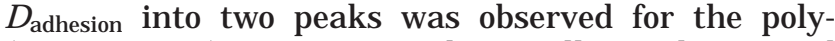
(HEMA-g-EG) ${ }_{120 \mathrm{~K}}$ in $\mathrm{H}_{2} \mathrm{O}$ with a smaller peak centered at $\sim 60 \mathrm{~nm}$ and another larger peak at $\sim 190 \mathrm{~nm}$.

The probability distributions of $F_{\text {adhesion }}$ and $D_{\text {adhesion }}$ for single mol ecule poly(HEMA-g-EG) on retract in PBS are shown in Figure 11 and Table 3. The means values were as follows: $\left\langle\mathrm{F}_{\text {adhesion }}\right\rangle=0.39 \pm 0.18 \mathrm{nN}$ and $\left\langle\mathrm{D}_{\text {adhesion }}\right\rangle=42.31 \pm 6.64 \mathrm{~nm}$ for the $16 \mathrm{~K}$, and $\left\langle\mathrm{F}_{\text {adhesion }}\right\rangle$ $=0.16 \pm 0.13 \mathrm{nN}$ and $\left\langle\mathrm{D}_{\text {adhesion }}\right\rangle=77.17 \pm 27.79 \mathrm{~nm}$ for the $120 \mathrm{~K}$. Once again, the distance distributions were generally less than $L_{\text {contour }}$ calculated from the known $M W$ and greater than the known $R_{g}$ measured by LS in DMF. A bimodal distribution of $D_{\text {adhesion }}$ was observed for the poly(HEMA-g-EG) ${ }_{120 K}$ in PBS with one larger peak centered at $\sim 60 \mathrm{~nm}$ and another smaller and broader peak at $\sim 125 \mathrm{~nm}$, suggesting two specific regions of preferred binding along the polymer chain. Even though the polymer-probe tip binding is expected to be nonspecific, this phenomenon could arise if the polymers were initially in conformations on the substrate (due to polymer intramolecular interactions or polymer-substrate interactions) that would facilitate binding to these specific regions of the polymer chains. 

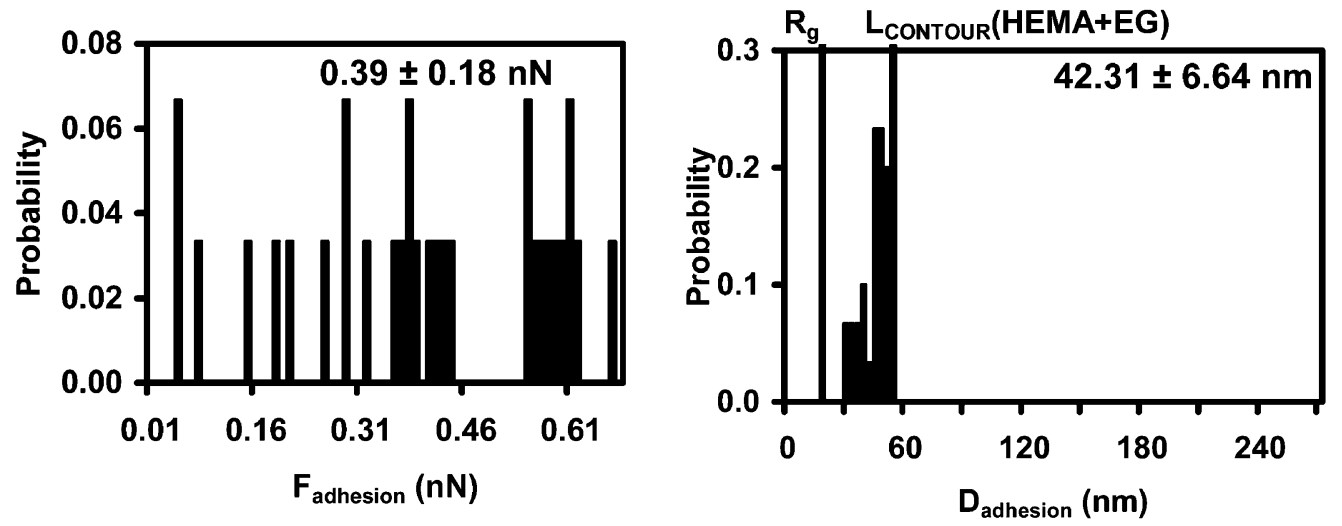

b
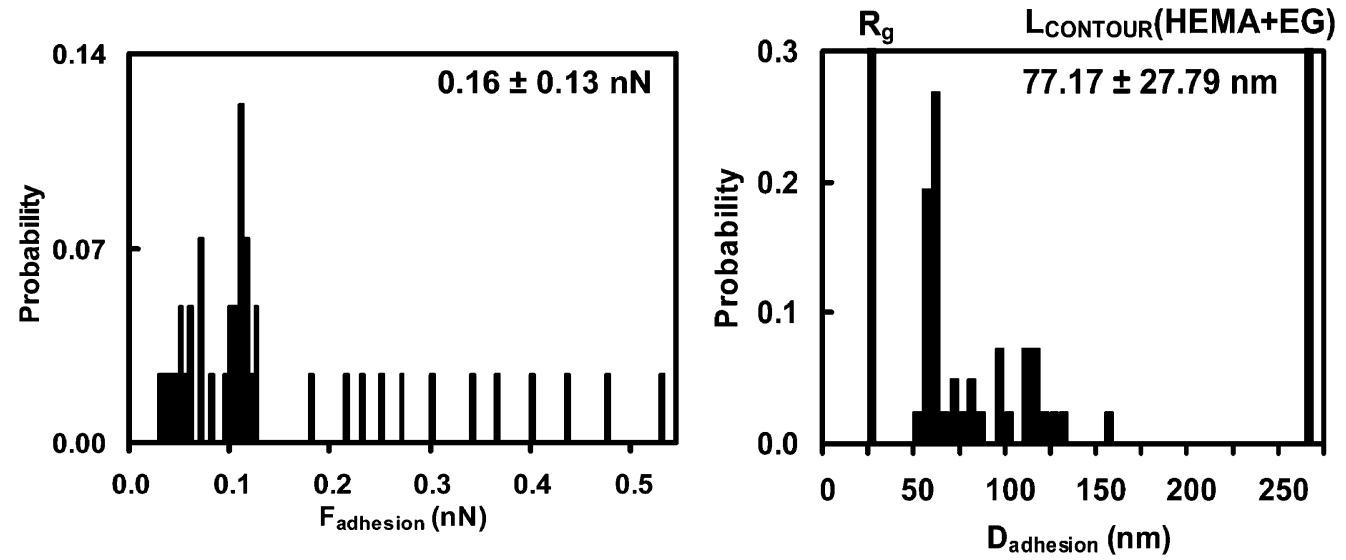

Figure 11. Probability distributions of single molecule detachment forces and distances for (a) poly(HEMA-g-EG) $16 \mathrm{~K}$ and (b) poly(HEMA-g-EG) $)_{120 \mathrm{~K}}$ in PBS. Inset numerical values are the calculated mean and standard deviation for that dataset.

Unfortunately, as mentioned previously, it is suspected that the AFM imaging of the chains on the substrate does not yield accurate information on the equilibrium conformation being probed in the nanomechanical measurements.

\section{Discussion}

The combination of PHEMA and PEG into a block copolymer form has just recently started to be explored in the context of improved aqueous, solubility, hydrophilicity, and biocompatibility ${ }^{54}$ and for applications such as nanoreactors for nanoparticle preparation. ${ }^{55}$ Unique equilibrium conformations of poly(HEMA-g-EG) mushrooms are expected due to the amphiphilic nature of each of the monomers in aqueous solution. Reorientation of segments on the surface to maximize exposure of hydrophilic groups to water (in particular the EG side chains) and hydrophobic groups to the underlying hydrophobic Au substrate is expected. The advancing contact angles for both the 16K and 120K polymers were similar to the Au substrate, which indicated the polymers were initially oriented in such a way that some hydrophobic groups were exposed to air. However, the receding contact angles for the polymer mushroom substrates were much smaller than that of the Au substrate, so the polymer conformations reoriented in a way that the hydrophilic groups were exposed to water. F or PEG, it has been postulated that the majority of chain segments exist in a trans-trans-gauche (ttg) conformation that is stabilized by water binding, leading to an $(11 / 2)$ helical supramolecular structure that is similar to, but more expanded than, that found for the crystalline form. Figure 12 is a schematic that summarizes some of the possible noncovalent interactions for the poly(HEMA-g-EG) in aqueous solution which ultimately will determine the equilibrium conformation of the copolymer and include intramolecular $\mathrm{H}$-bonding, intermolecular $\mathrm{H}$-bonding with $\mathrm{HOH}$, and hydrophobic interactions.

Nanoscale Surface I nteractions of End-Grafted Poly(HE MA-g-E G)Mushrooms on Approach. Prior work reported in the literature related to the approach data presented in this study include nanomechanical experiments on thiol end-grafted PEG2K brushes on Au using a hydrophobically modified C16 probe tip which show a purely repulsive interaction on approach for $D$ $<12 \mathrm{~nm} .{ }^{56}$ In our experiments, in addition to the EDL repulsion imparted by the $86-90 \%$ surface area taken up by the Au substrate, the $10 \%-14 \%$ of the surface area covered by the graft copolymer mushrooms may contribute configurational entropy, enthal pic deformability due to noncovalent intramolecular interactions and/or polymer-solvent interactions, and hydration repulsion as well as attractive van der Waals and hydrophobic interactions depending on the polymer surface conformation. In PBS the poly(HEMA-g-EG) $16 \mathrm{~K}$ shows a net attractive force for $\mathrm{D}<\sim 10 \mathrm{~nm}\left(\mathrm{R}_{\mathrm{g}}(\mathrm{DMF})=18.5 \mathrm{~nm}\right.$ with $R_{g}(P E G 2 K$ side chains $\left.)=3.6 \mathrm{~nm}\right), 56$ thus suggesting that the polymer is contributing enough van der Waals and/or hydrophobic interactions from exposed functional groups to outweigh the EDL repulsion imparted by the Au or the PEG2K. Since EDL simulations 


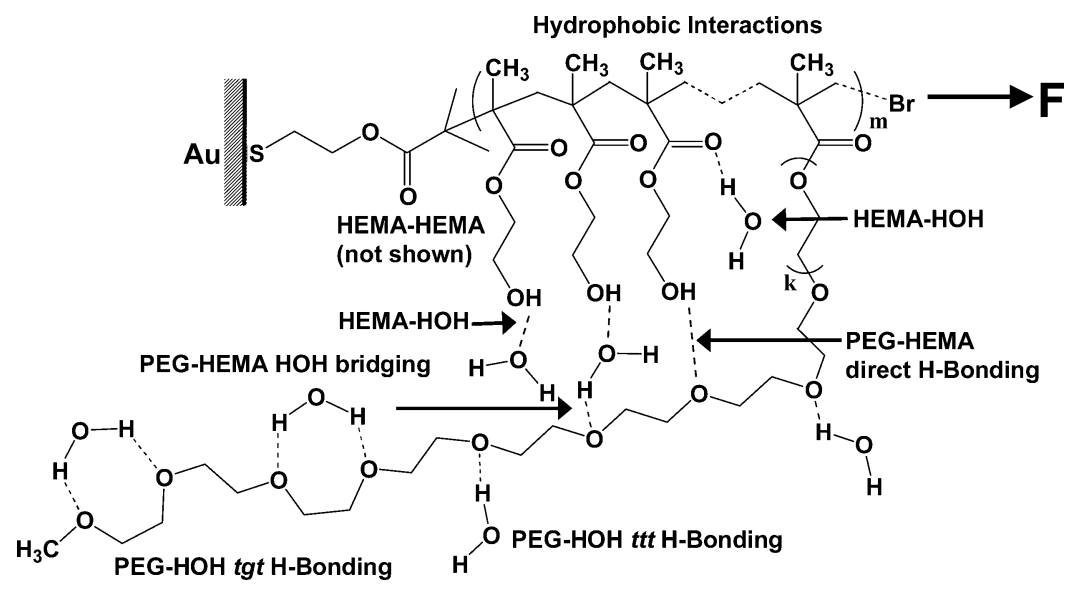

Figure 12. Possible noncovalent interactions for poly(HEMA-g-EG) in aqueous solution.

for the $\mathrm{Si}_{3} \mathrm{~N}_{4}$ Vs Au interaction could not be performed for the low IS conditions of the $\mathrm{H}_{2} \mathrm{O}$, it is unclear whether the dramatic increase in the magnitude of the repulsion compared to that of PBS is primarily due to the increased EDL repulsion of the Au or a conformational transition of the graft copolymer to a more expanded form. It is noted that there is a slight increase in the magnitude of the repulsion for the $120 \mathrm{~K}$ poly(HEMA-g-EG) compared to that for the 16K, suggesting that the polymer was contributing a component of the net interaction.

Molecular Elasticity of End-Grafted Poly(HEMAg-E G)Mushrooms on Retract. As mentioned previously, the poly(HEMA-g-EG) ${ }_{120 k}$ data are more amenable to inter pretation due to the longer $L_{\text {contour }}$ of $\sim 264$ $\mathrm{nm}$, which enables single macromol ecule extensions out to distances beyond the range of nonspecific tip-surface interactions ( $\sim 40 \mathrm{~nm})$. Clearly, for experiments that showed extensions out to hundreds of nanometers, such as those examples given in Figure $8 b, d$, what is being measured is primarily the PHEMA backbone since $\mathrm{L}_{\text {contour }}(\mathrm{PEG} 2 \mathrm{~K}) \sim 20 \mathrm{~nm}$. The single mol ecule el asticity profiles for the poly(HEMA-g-EG) are observed to be very different from the known unique nanomechanical behavior of PEG in PBS, which exhibits increased force in aqueous solution (relative to nonpolar solvents) and deviation from standard FJ C models due to the presence of a fully reversible, strain-induced conformational transition from a tightly $\mathrm{H}$-bonded, water-bound, contracted ttg state to the more extended ttt state. ${ }^{57} \mathrm{H}$ ence, even though the known PEG Kuhn length is similar (a $=0.7 \mathrm{~nm})^{57}$ to that observed for the poly(HEMA-g-EG), the graft copolymer is in a conformation that requires much less force for extension than PEG homopolymer, suggesting a smaller number and/or smaller magnitude of the noncovalent inter- and intramolecular interactions al ong the HEMA backbone relative to PEG, which is quite interesting given the large number of hydrophobic groups present on the HEMA backbone. Given this relatively low value of the resisting force to extension, it seems that in PBS the PEG side chains are quite effective in causing local expansion of the PHEMA backbone by overcoming hydrophobic collapsing forces relative to the PHEMA homopolymer. Comparison of the single molecule elasticity profiles for a single poly(HEMA-g-EG) $)_{120 \mathrm{~K}}$ in different solvents indicated that the Kuhn length decreased by $\sim 50 \%$ and the segmental spring constant increased by $\sim 60 \%$ from the $\mathrm{H}_{2} \mathrm{O}$ to PBS solvent. Since the PEG chains are still well-solvated in PBS, one explanation for this behavior is that in PBS the salt ions compete for and weaken the inter-and/or intramolecular $\mathrm{H}$-bonding that is present along the PHEMA backbone, shown schematically in Figure 12, causing a local contraction and an increased segmental stiffness due to the reduced noncoval ent nature of the segments.

\section{Conclusions}

In this study, a unique graft copolymer, SH-poly(HEMA-g-EG), was synthesized by the ATRP method and then characterized by ${ }^{1} \mathrm{H}$ NMR, GPC, and LS. The polymer was coval ently end-grafted to an Au substrate at low enough grafting densities to produce wellseparated individual "mushrooms" which were characterized by TMAFM imaging and contact angle measurements. SMFS was then employed to measure the single polymer extensional elastic properties in PBS and $\mathrm{H}_{2} \mathrm{O}$. In both solvents, the polymer behaved as an extensible FJ C with $\mathrm{a}=0.52 \pm 0.09 \mathrm{~nm}, \mathrm{k}_{\text {segment }}=10.5 \pm 3.3 \mathrm{~N} / \mathrm{m}$ in PBS and $\mathrm{a}=1.03 \pm 0.01 \mathrm{~nm}, \mathrm{k}_{\text {segment }}=4.2 \pm 0.5$ $\mathrm{N} / \mathrm{m}$ for the $\mathrm{H}_{2} \mathrm{O}$. Comparison to the known single molecule elasticity behavior for the PEG homopolymer suggests a smaller number and/or smaller magnitude of the noncovalent inter- and intramolecular interactions along the HEMA backbone and that even at this Iow PEG side chain grafting density, the side chains are still quite effective in causing local expansion of the PHEMA backbone by overcoming hydrophobic collapsing forces relative to the PHEMA homopolymer. Since the PEG chains are still well-solvated in PBS, one explanation for the variation in nanomechanical properties with solvent is that in PBS the salt ions compete for and weaken the intermolecular $\mathrm{H}$-bonding present along the PHEM A backbone, causing a local contraction and an increased segmental stiffness due to the reduced noncovalent nature of the segments. Ongoing studies include preparation SMFS of PHEMA homopolymer, poly(HEMA-g-EG) block copolymers with different side chain density and different PEG lengths, and other side chains with varying hydrophilicity/phobicity such as introduction of $-\mathrm{N}=,-\mathrm{COOH}$, and $-\mathrm{CH}_{2}-$ groups.

Acknowledgment. The authors thank the NSF (PECASE, 0094194) and 3M for financial support and Dr. T. Alan Hatton's Group for providing LS help in the Department of Chemical Engineering, Dr. Anne M. Mayes' Group for providing GPC help in the Department of Materials Science and Engineering at MIT, and Delphine Dean for providing EDL simulations. 


\section{References and Notes}

(1) Kim, P.; Lieber, C. M. Science 1999, 286, 2148.

(2) Reed, M. A.; Zhou, C.; Muller, C. J .; Burgin, T. P.; Tour, J. M. Science 1997, 278, 252.

(3) Yanson, A. I.; Bollinger, G. R.; van den Brom, H. E.; Agrait, N.; van Ruitenbeek, J. M. Nature (London) 1998, 395, 783.

(4) Zhang, W.; Zhang, X. Prog. Polym. Sci. 2003, 28, 1271-1295.

(5) Ortiz, C.; Hadziioannou, G. Macromol ecules 1999, 32, 780787.

(6) Ludwig, M.; Rief, M.; Li, H.; Oesterhelt, F.; Gautel, M.; Gaub, H. E. Appl. Phys. A 1999, 68, 173-176.

(7) Szycher, M. High Performance Biomaterials: A Comprehensive Guide to Medical and Pharmaceutical Applications; Technomic Publishing: Lancaster, PA, 1991.

(8) Stoy, V. A.; Kliment, C. A. Hydrogels: Specialty Plastics for Biomedical, Pharmaceutical and Industrial Applications; Technomic Publishing: Lancaster, PA, 1990.

(9) Khan, A. J .; Percival, S. P. J . Cataract. Refract. Surg. 1999, 25, 1404-1407.

(10) Leckband, D. Annu. Rev. Biophys. Biomol. Struct. 2000, 29 $1-26$

(11) Ratner, B. D.; Hoffman, A. S.; Schoen, F. J .; Lemons, J . E. Biomaterials Science: An Introduction to Materials in Medicine: Academic Press: San Diego, CA, 1996.

(12) Park, K.; Shalaby, W.; Park, H. Biodegradable Hydrogels for Drug Delivery: Technomic Publishing: Lancaster, PA, 1993.

(13) Ghi, P. Y.; Hill, D. J . T.; Whittaker, A. K. Biomacromol. Sum 2001, 2, 504-510.

(14) Harris, J. M., Ed. Poly(ethylene glycol) Chemistry: Biotechnical and Biomedical Applications; Plenum: New York, 1992.

(15) Wu, S. Polymer Interfaces and Stability; Marcel Dekker: New York, 1982.

(16) Israelachvili, J .; Adams, G. E. J . Chem. Soc., Faraday Trans. 1 1978, 74, 975-1001.

(17) Kretschmann, E.; Rather, H. Z. Naturforsch., A 1968, 241, 2135-2136.

(18) Kretschmann, E. Z. Phys. 1971, 241, 313-324

(19) Lavrik, N. A.; Leckband, D. Langmuir 2000, 16, 1842-1851.

(20) Ahrens, H.; Baekmark, T. R.; Merkel, R.; Schmitt, J .; Graf, K.: Raiteri, R.; Helm, C. A. Chem. Phys. Chem. 2000, 1, 101.

(21) Cao, B.; Kim, M. W. Faraday Discuss. 1994, 98, 245.

(22) Kim, M. Colloids Surf. A. 1997, 128, 145.

(23) Seferis, J. C. In Polymer Handbook, 4th ed.; Brandrup, J., Immergut, E. H., Grulke, E. A., Eds.; Wiley-Interscience: New York, 1999; $p$ VI 582.

(24) (a) Pinchuk, L.; Eckstein, E. C.; van der Mark, M. R. J. Biomed. Mater. Res. 1984, 18, 671. (b) Weaver, J. V. M.; Bannister, I.; Robinson, K. L.; Bories-Azeau, X.; Armes, S. P.; Smallridge, M.; McKenna, P. Macromolecules, in press.

(25) Holly, F. J .; Refojo, M. F. J . Biomed. Mater. Res. 1975, 9, 315-326.

(26) Matyjaszewski, K.; Coessens, V.; Nakagawa, Y.; Xia, J .; Qiu, J .; Gaynor, S.; Coca, S.; J asieczek, C. In Functional Polymers: Modern Synthetic Methods and Nove Structures; Patil A. O., Schulz, D. N., Novak, B. M., Eds.; American Chemical Society: Washington, DC, 1998; $\mathrm{p} 16$.

(27) Coessens, V.; Nakagawa, Y.; Matyjaszewski, K. Polym. Bull. (Berlin) 1998, 40, 135-142.

(28) Fuente, J . L. D. L.; Fernandez-Sanz, M.; Fernandez-Garcia, M.; Madruga, E. L. Macromol. Chem. Phys. 2001, 202, 25652571.
(29) Wootthikanokkhan, J.; Peesan, M.; Phinyocheep, P. Eur. Polym. J . 2001, 37, 2063-2071.

(30) Fuente, J . L. D. L.; Fernandez-Garcia, M.; Fernandez-Sanz, M.; Madruga, E. L. J . Polym. Sci., Part A: Polym. Chem 2001, 39, 3443-3450.

(31) Yu, Q.; Zeng, F.; Zhu, S. Macromolecules 2001, 34, 16121618

(32) Zhang, X.; Xia, J .; Matyjaszewski, K. Macromolecules 2000 $33,2340-2345$.

(33) Hedrick, J. L.; Trollsas, M.; Hawker, C. J .; Atthoff, B.; Claesson, H.; Heise, A.; Miller, R. D. Macromolecules 1998, 31, 8691-8705.

(34) J ankova, K.; Chen, X.; Kops, J .; Batsberg, W. Macromol ecules 1998, 31, 538-541.

(35) Wang, J.; Matyjaszewski, K. Macromol ecules 1995, 28, 79017910.

(36) Carrot, G.; Hilborn, J .; Hedrick, J . L.; Trollsas, M. Macro molecules 1999, 32, 5171-5173.

(37) Carrot, G.; Hilborn, J. G.; Trollsas, M.; Hedrick, J. L. Macromolecules 1999, 32, 5264-5269.

(38) Shaltiel, S. Biochem. Biophys. Res. Commun. 1967, 29, 178183.

(39) Michielsen, S. In Polymer Handbook, 4th ed.; Brandrup, J ., Immergut, E. H., Grulke, E. A., Eds.; Wiley-Interscience: New York, 1999; p VII 547

(40) Elias, H.-G. Macromolecules; Plenum Press: New York, 1977.

(41) J iang, X.-P.; Ortiz, C.; Hammond, P. T. Langmuir 2002, 18, $1131-1143$

(42) Seog, J .; Dean, D.; Plaas, A. H. K.; Wong-Palms, S.; Grodzinsky, A. J .; Ortiz, C. Macromol ecules 2002, 35, 5601-5615.

(43) Rixman, M. A.; Dean, D.; Macias, C. E.; Ortiz, C. Langmuir 2003, 19, 6202-6218

(44) Rixman, M. A.; Dean, D.; Ortiz, C. Langmuir 2003, 19, 93579372.

(45) Bergstrom, L.; Bostedt, E. Colloids Surf. 1990, 49, 183-197.

(46) Senden, T. J .; Drummond, C. J . Colloids Surf. 1995, 94, 29 51.

(47) Tsukruk, V. V.; Bliznyuk, V. N. Langmuir 1998, 14, 446455.

(48) Ng, L. J .; Grodzinsky, A. J .; Ortiz, C. In The American Chemical Society National Meeting, Division of Polymer Chemistry, Polymer Preprints; Boston, MA, 2002; Vol. 224, p 351.

(49) Flory, P. J . Statistical Mechanics of Chain Molecules; Hanser: Munich, 1988.

(50) Parsegian, V. A.; D. G. Biophys. I 1972, 12, 1192-1204.

(51) Derjaguin, B. V. Kolloid Z. 1934, 69, 155-164.

(52) Dean, D.; Seog, J .; Ortiz, C.; Grodzinsky, A. J . Langmuir 2003, 19, 5526-5539.

(53) Smith, S. B.; Finzi, L.; Bustamante, C. Science 1992, 258, $1122-1126$

(54) Okano, T.; Uruno, M.; Sugiyama, N.; Shimada, M.; Shinohara, I.; Kataoka, K.; Sakurai, Y. J. Biomed. Mater. Res. 1986, 20, 1035-1047.

(55) Liu, S.; Weaver, J . V. M.; Save, M.; Armes, S. P. Langmuir 2002, 18, 8350-8357.

(56) Feldman, K.: Haehner, G.; Spenser, N. D.: Harder, P.; Grunze, M. J. Am. Chem. Soc. 1999, 121, 10134-10141.

(57) Oesterhelt, F.; Rief, M.; Gaub, H. E. New J. Phys. 1999, 1, 6.1-6.11.

MA035065B 